Supplemental information for:

\title{
Invoking side-chain functionality for the mediation of regioselectivity during ring-opening polymerization of glucose carbonates
}

\author{
Yue Song, ${ }^{\dagger}$ Xin Yang, ${ }^{\dagger, \#}$ Yidan Shen,${ }^{\S}$ Mei Dong, ${ }^{\dagger}$ Yen-Nan Lin,${ }^{\dagger, \|}$ Michael B. Hall, ${ }^{\dagger, \#}$ \\ and Karen L. Wooley $*,+, t, \xi$
}
†Departments of Chemistry, ${ }^{\star}$ Chemical Engineering, and ${ }^{\S}$ Materials Science \& Engineering, Texas A\&M University, College Station, Texas 77842, USA
"Laboratory for Molecular Simulation, Texas A\&M University, College Station, Texas 77842, USA

${ }^{\|}$College of Medicine, Texas A\&M University, Bryan, Texas 77807, USA

*Corresponding author: wooley@chem.tamu.edu 
I. Experimental procedures and characterization data ...................................................................... 4

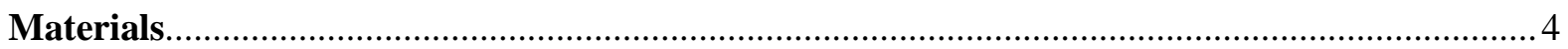

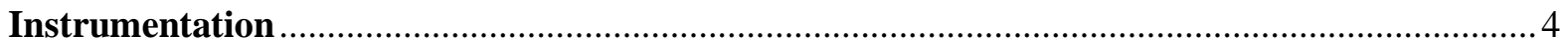

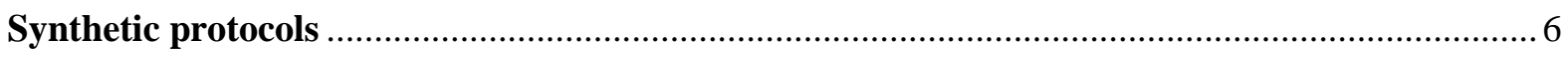

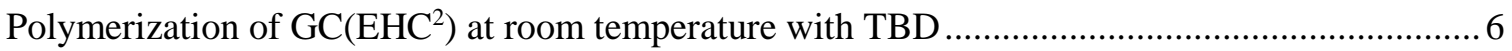

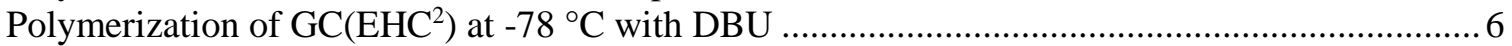

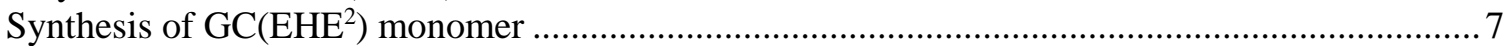

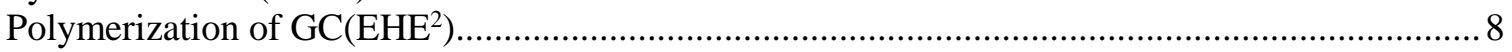

Oligomerization of $\mathrm{GC}\left(\mathrm{EHE}^{2}\right)$ and isolation of the unimers and dimers...................................

Oligomerization of $\mathrm{GC}(\mathrm{OMe})$ and separation of $\mathrm{GC}(\mathrm{OMe})$ oligomers ....................................... 10

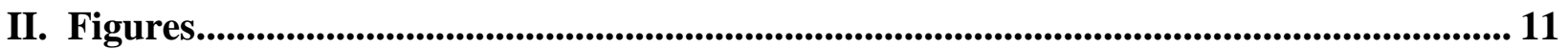

Figure S1. A full view of COSY spectrum $(500 \mathrm{MHz})$ of $\mathrm{GC}\left(\mathrm{EHC}^{2}\right)$ unimer in $\mathrm{CDCl}_{3} \ldots \ldots \ldots \ldots \ldots . . . . .11$

Figure S2. HSQC spectra $\left(500 \mathrm{MHz}\right.$ for $\left.{ }^{1} \mathrm{H}\right)$ of $\mathrm{GC}\left(\mathrm{EHC}^{2}\right)$ unimer in $\mathrm{CDCl}_{3}$. (a) Full spectrum, and

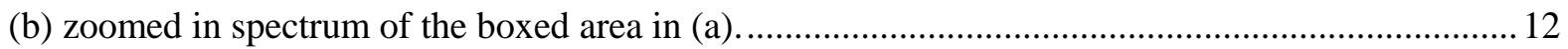

Figure S3. HMBC full spectrum (400 $\mathrm{MHz}$ for $\left.{ }^{1} \mathrm{H}\right)$ of $\mathrm{GC}\left(\mathrm{EHC}^{2}\right)$ unimer in $\mathrm{CDCl}_{3}$.................... 13

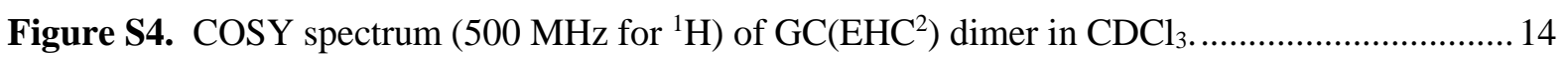

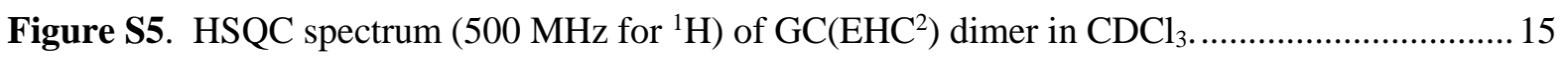

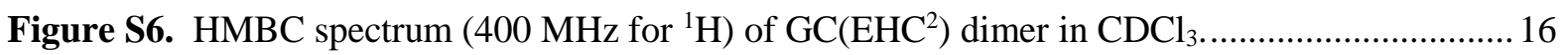

Figure S7. COSY spectra (500 MHz) of $\mathrm{GC}\left(\right.$ neoPC ${ }^{2}$ ) unimer in $\mathrm{CDCl}_{3}$. (a) Full spectrum, and (b)

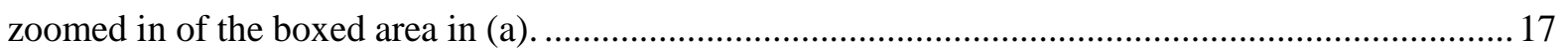

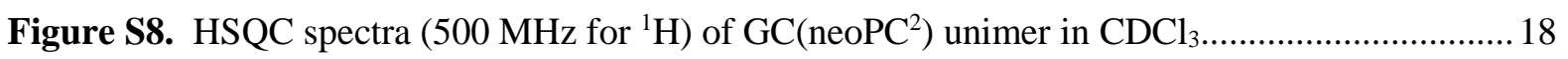

Figure S9. HMBC spectra $\left(400 \mathrm{MHz}\right.$ for $\left.{ }^{1} \mathrm{H}\right)$ of $\mathrm{GC}\left(\right.$ neoPC $\left.{ }^{2}\right)$ unimer in $\mathrm{CDCl}_{3}$........................... 19

Figure S10. HMBC spectrum (400 MHz for $\left.{ }^{1} \mathrm{H}\right)$ of $\mathrm{GC}\left(\right.$ neoPC $\left.{ }^{2}\right)$ unimer in $\mathrm{CDCl}_{3}$..................... 20

Figure S11. COSY spectrum (500 $\mathrm{MHz}$ for $\left.{ }^{1} \mathrm{H}\right)$ of $\mathrm{GC}\left(\right.$ neoPC $\left.{ }^{2}\right)$ dimer in $\mathrm{CDCl}_{3}$.......................21

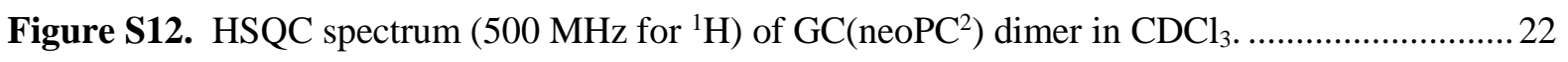

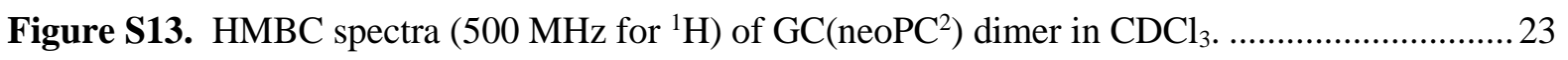

Figure S14. ${ }^{1} \mathrm{H}(500 \mathrm{MHz}) \&{ }^{13} \mathrm{C}(126 \mathrm{MHz}) \mathrm{NMR}$ spectra of $\mathrm{GC}\left(\mathrm{EHE}^{2}\right)$ monomer in $\mathrm{CDCl}_{3} \ldots \ldots . .24$

Figure S15. SEC trace of the oligomer mixture and MALDI-TOF spectrum of isolated unimers of

$\mathrm{GC}\left(\mathrm{EHE}^{2}\right)$

Figure S16. TLC plate images of the regioisomeric unimers of $\mathrm{GC}\left(\mathrm{EHE}^{2}\right)$ after separation in $20 \%$ ethyl acetate $/ 80 \%$ hexanes (top fraction: $C-O 4$ cleavage product, isomer $\mathbf{I}, \mathrm{Rf}=0.79$; bottom

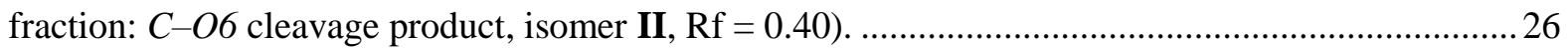

Figure S17. ${ }^{1} \mathrm{H}$ NMR, COSY and HSQC spectra of $\mathrm{GC}\left(\mathrm{EHE}^{2}\right)$ unimer regioisomer I in $\mathrm{CDCl}_{3} \ldots . .27$ 
Figure S18. ${ }^{1} \mathrm{H}$ NMR, COSY and HSQC spectra of $\mathrm{GC}\left(\mathrm{EHE}^{2}\right)$ unimer regioisomer II in $\mathrm{CDCl}_{3} \ldots 28$

Figure S19. HMBC spectrum (400 MHz for $\left.{ }^{1} \mathrm{H}\right)$ of $\mathrm{GC}\left(\mathrm{EHE}^{2}\right)$ unimer isomer $\mathbf{I}$ in $\mathrm{CDCl}_{3} \ldots \ldots \ldots \ldots . .29$

Figure S20. HMBC spectrum (400 MHz for $\left.{ }^{1} \mathrm{H}\right)$ of $\mathrm{GC}\left(\mathrm{EHE}^{2}\right)$ unimer isomer II in $\mathrm{CDCl}_{3} \ldots \ldots \ldots . . . .30$

Figure S21. (a) ${ }^{1} \mathrm{H}(500 \mathrm{MHz})$ and (b) ${ }^{13} \mathrm{C}(126 \mathrm{MHz}) \mathrm{NMR}$ spectra of $\mathrm{GC}\left(\mathrm{EHE}^{2}\right)$ dimer isomer

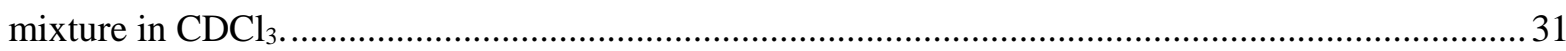

Figure S22. ${ }^{1} \mathrm{H}$ NMR $\left(400 \mathrm{MHz}, \mathrm{CDCl}_{3}\right)$ spectra of $\mathrm{GC}(\mathrm{OMe})$ unimers and dimers. ......................32

Figure S23. (a-b) ${ }^{13} \mathrm{C}$ NMR $\left(100 \mathrm{MHz}, \mathrm{CDCl}_{3}\right)$ spectra of $\mathrm{GC}(\mathrm{OMe})$ unimers and dimers. Red curve (dimers) in (b) presenting a 1:1:1:1 carbonyl peak ratio for $\mathbf{5}$ and $\mathbf{5}^{\prime}$. (c) The structures of unimers and dimers.

Figure S24. ${ }^{13} \mathrm{C}$ NMR $\left(126 \mathrm{MHz}, \mathrm{CDCl}_{3}\right)$ spectra of $\mathrm{PGC}\left(\mathrm{EHC}^{2}\right)$. The polymerization was conducted at room temperature. 34

Figure S25. ${ }^{13} \mathrm{C}$ NMR spectrum of $\mathrm{PGC}\left(\mathrm{EHC}^{2}\right)$ synthesized using DBU at $-78{ }^{\circ} \mathrm{C}$. 34

Figure S26. Four pathways $(a, b, c, d)$ of the initiation step of the ROP of 4,6-D-glucose carbonate, catalyzed by TBD and initiated by $4-\mathrm{MeBnOH}$. $\mathrm{R}=$ side chain protecting group, alkyl or alkoxylcarbonyl groups.

Figure S27. Gibbs free energy profile for the ring-opening initiation of glucose carbonate monomers, $\mathbf{R}=$ ethyloxycarbonyl, catalyzed by TBD and initiated by 4-MeBnOH... .36

Figure S28. Gibbs free energy profile for the ring-opening initiation of glucose carbonate monomers, $\mathbf{R}=$ methoxyl, catalyzed by $\mathrm{TBD}$ and initiated by $4-\mathrm{MeBnOH}$.

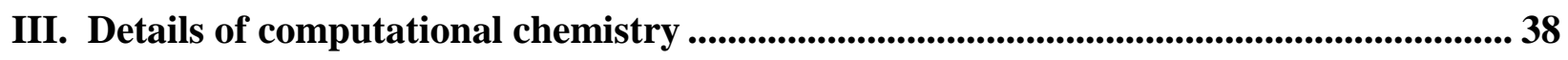

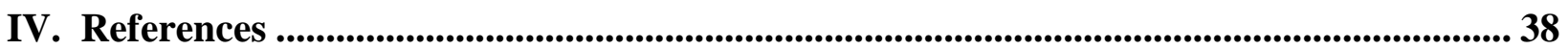




\section{Experimental procedures and characterization data}

\section{Materials}

1,5,7-Triazabicyclo[4.4.0]dec-5-ene (TBD) and 2-ethylhexyl chloroformate were used as received from TCI America (Portland, OR). 4-Methylbenzyl alcohol was purified by recrystallization from petroleum ether and stored in a glovebox under Ar atmosphere. Amberlyst ${ }^{\circledR} 15(\mathrm{H})$, ion exchange resin and $N, N, N^{\prime}, N^{\prime}$-tetramethylethylenediamine, $99 \%$ were purchased from Alfa Aesar, Thermo Fisher Scientific (Ward Hill, MA). Triphosgene was used as received from Oakwood Products, Inc. (Estill, SC). Dichloromethane (DCM) was purified by a solvent purification system (J. C. Meyer Solvent Systems, Inc., Laguna Beach, CA). Other reagents were used as received from Sigma-Aldrich, Co. (St. Louis, MO) unless otherwise noted.

\section{Instrumentation}

${ }^{1} \mathrm{H}$ NMR, ${ }^{13} \mathrm{C}$ NMR, COSY, ${ }^{1} \mathrm{H}-{ }^{13} \mathrm{C}$ HSQC and ${ }^{1} \mathrm{H}-{ }^{13} \mathrm{C}$ HMBC spectra were acquired on Varian Inova 500, Bruker 400, and Avance 500 spectrometers. Chemical shifts were referenced to the solvent resonance signals.

Size exclusion chromatography (SEC) eluting with THF was conducted on a Waters Chromatography, Inc. (Milford, MA) system equipped with an isocratic pump (model 1515), a differential refractometer (model 2414), and a four-column set, including a $5 \mu \mathrm{m}$ Guard column $(50 \times 7.5 \mathrm{~mm})$, a PLgel $5 \mu \mathrm{m}$ Mixed C column $(300 \times 7.5 \mathrm{~mm}$, Agilent Technologies $)$ and two

Styragel ${ }^{\circledR}$ columns (500 $\AA$ and $104 \AA$, $300 \times 7.5$ mm, Waters Chromatography, Inc.). The system was equilibrated at $40^{\circ} \mathrm{C}$ in $\mathrm{THF}$ with the flow rate set to $1.0 \mathrm{~mL} / \mathrm{min}$. Data collection and analysis were performed with Waters Breeze ${ }^{\mathrm{TM}}$ software. Molar masses were determined relative to polystyrene standards (615-442800 Da) purchased from Polymer Laboratories, Inc. (Amherst, MA). Polymer/oligomer solutions were prepared at a concentration of $c a .3 \mathrm{mg} / \mathrm{mL}$ with 0.05 vol\% toluene added as a flow marker, and an injection volume of $200 \mu \mathrm{L}$ was used.

Preparative size exclusion chromatography (prep SEC) eluting with chloroform was conducted on a JAI LC-9230II NEXT Chromatography, Inc. (Japan) system equipped with a reciprocating double plunger pump (model P-9104B), a UV-vis 4ch NEXT detector at four wavelengths (254 $\mathrm{nm}, 280 \mathrm{~nm}, 300 \mathrm{~nm}, 330 \mathrm{~nm}$ ), and a two-column set, including a JAIGEL-H 40P Guard column 
and a JAIGEL-2H-40 HPLC column. The system was equilibrated at room temperature in chloroform with the flow rate set to $14.0 \mathrm{~mL} / \mathrm{min}$. Data collection and analysis were performed with JAI Scan ${ }^{\mathrm{TM}}$ software. Polymer solutions were prepared at a concentration of $c a .10 \mathrm{mg} / \mathrm{mL}$ in chloroform and an injection volume of $5 \mathrm{~mL}$ was used.

Fourier transform infrared (FT-IR) spectra were recorded on an IR Prestige 21 system (Shimadzu Corp., Japan), equipped with an attenuated total reflectance (ATR) accessory, and analyzed using IRsolution v. 1.40 software.

Electrospray ionization mass spectrometry (ESI-MS) experiments were performed using a Thermo Scientific Q Exactive Focus. The sample was directly infused at a flow rate of $10 \mu \mathrm{L} / \mathrm{min}$. The Q-Exactive Focus HESI source was operated in full MS in positive mode. The mass resolution was tuned to $70000 \mathrm{FWHM}$ at m/z 200. The spray voltage was set to $3.75 \mathrm{kV}$, and the sheath gas and auxiliary gas flow rates were set to 7 and 0 arbitrary units, respectively. The transfer capillary temperature was held at $320^{\circ} \mathrm{C}$. Exactive Series $2.8 \mathrm{SP} 1 / \mathrm{Xcalibur} 4.0$ software was used for data acquisition and processing.

Thermogravimetric analysis (TGA) was performed under an $\mathrm{N}_{2(\mathrm{~g})}$ atmosphere using a MettlerToledo model TGA2/1100/464 from $25-500{ }^{\circ} \mathrm{C}$ with a heating rate of $10{ }^{\circ} \mathrm{C} / \mathrm{min}$. Data were analyzed using Mettler-Toledo STAR ${ }^{\mathrm{e}}$ v. 15.00a software.

Glass transitions $\left(T_{\mathrm{g}}\right)$ were measured by differential scanning calorimetry (DSC) on a Mettler-

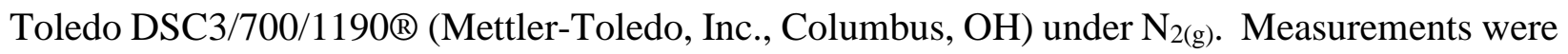
performed with a heating rate of $10{ }^{\circ} \mathrm{C} / \mathrm{min}$ and analyzed using Mettler-Toledo Star ${ }^{\mathrm{e}}$ v. 15.00a software. The $T_{\mathrm{g}}$ was taken as the midpoint of the inflection tangent of the third heating scan. 


\section{Synthetic protocols}

The synthesis of $\mathrm{PGC}\left(\mathrm{EHC}^{2}\right), \mathrm{PGC}\left(\right.$ neoPC $\left.{ }^{2}\right)$ using $\mathrm{TBD}$ at $-78^{\circ} \mathrm{C}$, synthesis and fractionation of the unimers and dimers of $\mathrm{GC}\left(\right.$ neoPC $\left.^{2}\right)$ and $\mathrm{GC}\left(\mathrm{EHC}^{2}\right)$ have been reported in previous work. ${ }^{1}$

\section{Polymerization of GC(EHC $\left.{ }^{2}\right)$ at room temperature with TBD}

A solution of $\mathrm{GC}\left(\mathrm{EHC}^{2}\right)$ monomer $(59.0 \mathrm{mg})$ and 4-methylbenzyl alcohol $(0.32 \mathrm{mg}, 3.2 \mathrm{mg} / \mathrm{mL}$ in DCM, $0.1 \mathrm{~mL}$ ) were prepared in a glovebox in a vial equipped with a stir bar at $30{ }^{\circ} \mathrm{C}$. A solution of TBD $(7.4 \mathrm{mg} / \mathrm{mL}$ in DCM, $0.05 \mathrm{~mL})$ was injected to the reaction mixture, and the reaction was allowed to stir at $30^{\circ} \mathrm{C}$ for $3 \mathrm{~min}$, followed by quenching by adding Amberlyst® 15 $\mathrm{H}$-form resin. The product was purified by precipitation into methanol twice and dried under vacuum to afford the polymer as a white solid $(25 \mathrm{mg}) .{ }^{1} \mathrm{H} \mathrm{NMR}\left(500 \mathrm{MHz}, \mathrm{CDCl}_{3}\right) \delta 7.28,7.16$ $\left(\mathrm{AB}_{\mathrm{q}}, J=8 \mathrm{~Hz}\right), 5.33(\mathrm{t}, \mathrm{J}=10 \mathrm{~Hz}, 1 \mathrm{H}), 5.30(\mathrm{~s}), 5.13(\mathrm{~m}), 5.00(\mathrm{br}), 4.79(\mathrm{~s}, 1 \mathrm{H}), 4.89-4.64(\mathrm{~m})$, $4.37-4.25(\mathrm{~m}), 4.06(\mathrm{~s}, 3 \mathrm{H}), 4.13-3.98(\mathrm{~m}, 2 \mathrm{H}), 3.43$ - $3.34(\mathrm{~m}), 2.34(\mathrm{~s}), 1.58(\mathrm{~m}), 1.41$ - 1.30 (m), 1.32 - $1.24(\mathrm{~m}), 0.87$ (m) ppm. $\left.{ }^{13} \mathrm{C} \mathrm{NMR} \mathrm{(126} \mathrm{MHz,} \mathrm{CDCl}_{3}\right) \delta 155.89,154.72,154.58$, 154.48, 154.42, 154.19, 153.94, 129.36, 128.71, 73.89, 73.59, 72.93, 71.30, 71.25, 71.16, 66.13, 55.75, 55.55, 53.57, 38.92, 38.87, 38.85, 30.19, 30.16, 30.13, 30.09, 30.06, 28.99, 28.94, 28.91, $23.55,23.52,23.49,23.47,23.06,15.41,14.18,14.17,10.96,10.93,10.90$ ppm. SEC (THF, 1 $\mathrm{mL} / \mathrm{min}$, polystyrene standards): $7.1 \mathrm{kDa}, Ð=1.18 . T_{\mathrm{g}}=95{ }^{\circ} \mathrm{C} . \mathrm{TGA}$ in $\mathrm{N}_{2(\mathrm{~g})}: 250-384{ }^{\circ} \mathrm{C}, 93 \%$ mass loss.

\section{Polymerization of $\mathrm{GC}\left(\mathrm{EHC}^{2}\right)$ at $-78^{\circ} \mathrm{C}$ with $\mathrm{DBU}$}

A solution of $\mathrm{GC}\left(\mathrm{EHC}^{2}\right)$ monomer $(55.0 \mathrm{mg})$ and 4-methylbenzyl alcohol $(0.28 \mathrm{mg}, 2.8 \mathrm{mg} / \mathrm{mL}$ in DCM, $0.1 \mathrm{~mL}$ ) were prepared in a vial equipped with a stir bar. The reaction mixture was connected to a Schleck line and cooled down to $-78^{\circ} \mathrm{C}$ in a dry ice-acetone bath. A solution of DBU $(7.5 \mathrm{mg} / \mathrm{mL}$ in DCM, $0.1 \mathrm{~mL})$ was injected to the reaction mixture, and the reaction was allowed to stir at $-78{ }^{\circ} \mathrm{C}$ for $12 \mathrm{~h}$, followed by quenching by adding an aliquot of acetic acid solution. The product was purified by precipitation into methanol twice and dried under vacuum to afford the polymer as a white solid $(9 \mathrm{mg}) .{ }^{1} \mathrm{H} \mathrm{NMR}\left(500 \mathrm{MHz}, \mathrm{CDCl}_{3}\right) \delta 7.28,7.16\left(\mathrm{AB}_{\mathrm{q}}, J=\right.$ $8 \mathrm{~Hz}), 5.33(\mathrm{~m}), 5.03$ - $4.95(\mathrm{~m}), 4.77$ - $4.66(\mathrm{~m}), 4.15$ - $3.99(\mathrm{~m}), 3.49$ - $3.33(\mathrm{~m}), 2.34(\mathrm{~s}), 1.43$ $-1.28(\mathrm{~m}), 1.31-1.23(\mathrm{~m}), 0.92-0.76(\mathrm{~m}) \mathrm{ppm} .{ }^{13} \mathrm{C} \mathrm{NMR}\left(126 \mathrm{MHz}, \mathrm{CDCl}_{3}\right) \delta 154.59,154.47$, $154.08,146.37,129.22$, 128.55, 97.88, 71.51, 69.30, 59.59, 56.24, 38.77, 30.00, 29.70, 28.87, 
28.78, 23.48, 23.39, 22.91, 21.18, 14.00, $10.82 \mathrm{ppm}$. SEC (THF, $1 \mathrm{~mL} / \mathrm{min}$, polystyrene standards): $5.9 \mathrm{kDa}, \emptyset=1.09$.

\section{Synthesis of GC(EHE $\left.{ }^{2}\right)$ monomer}

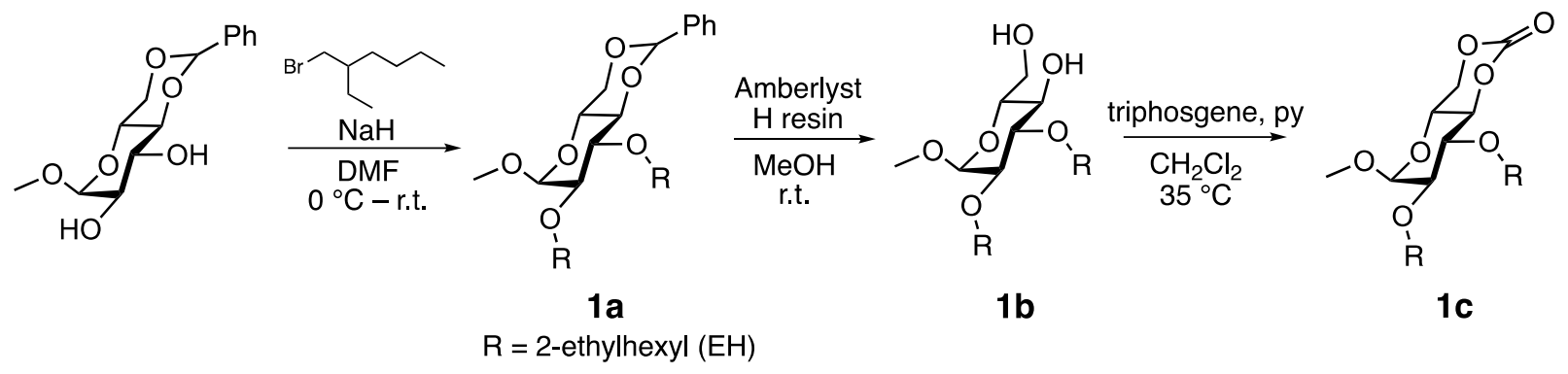

a. To a suspension mixture of $60 \mathrm{wt} \% \mathrm{NaH}$ in mineral oil $(2.3 \mathrm{~g}, 0.057 \mathrm{~mol})$ in dry DMF (100 $\mathrm{mL}$ ) was added methyl 4,6- $O$-benzylidene- $\alpha$-D-glucopyranoside $(2.0 \mathrm{~g}, 0.0071 \mathrm{~mol})$ in dry DMF $(50 \mathrm{~mL})$ dropwise at $0{ }^{\circ} \mathrm{C}$ over $20 \mathrm{~min}$ and the mixture was allowed to stir at room temperature for $1 \mathrm{~h}$. To the mixture was added 2-ethylhexyl bromide $(6.8 \mathrm{~mL}, 0.035 \mathrm{~mol})$ at $0{ }^{\circ} \mathrm{C}$ over $30 \mathrm{~min}$ and the mixture was allowed to stir at $0{ }^{\circ} \mathrm{C}$ for $1 \mathrm{~h}$. The mixture was allowed to warm to room temperature, stirred for $22 \mathrm{~h}$. The reaction was quenched by slowly adding water and extracted with dichloromethane. The collected organic layer was dried over $\mathrm{Na}_{2} \mathrm{SO}_{4}$ and concentrated under reduced pressure. The residue was purified by column chromatography (gradient ethyl acetate/hexanes) to afford the 1a methyl-2,3-O-2-ethylhexyl4,6- $O$-benzylidene- $\alpha$-D-glucopyranoside (yield: $0.44 \mathrm{~g}$ ) as a colorless liquid. ${ }^{1} \mathrm{H}$ NMR (500 $\left.\mathrm{MHz} \mathrm{CDCl}_{3}\right) \delta 7.54-7.47(\mathrm{~m}, 2 \mathrm{H}), 7.37(\mathrm{~m}, 3 \mathrm{H}), 5.56(\mathrm{~s}, 1 \mathrm{H}), 4.82(\mathrm{dd}, J=4,1 \mathrm{~Hz}, 1 \mathrm{H})$, $4.30(\mathrm{dd}, J=9,4 \mathrm{~Hz}, 1 \mathrm{H}), 3.88-3.71(\mathrm{~m}, 3 \mathrm{H}), 3.71(\mathrm{dd}, J=7,1 \mathrm{~Hz}, 1 \mathrm{H}), 3.68(\mathrm{~d}, J=6 \mathrm{~Hz}$, $1 \mathrm{H}), 3.68-3.56(\mathrm{~m}, 1 \mathrm{H}), 3.54(\mathrm{~m}, 2 \mathrm{H}), 3.53-3.44(\mathrm{~m}, 1 \mathrm{H}), 3.45(\mathrm{~s}, 3 \mathrm{H}), 3.36(\mathrm{dd}, J=9,4$ $\mathrm{Hz}, 1 \mathrm{H}), 1.60-1.47$ (m, 1H), $1.51-1.40$ (m, 1H), 1.29 (m, 19H), 0.99 (d, J=6.6 Hz), $0.96-$ $0.89(\mathrm{~m}, 5 \mathrm{H}), 0.93-0.80(\mathrm{~m}, 9 \mathrm{H}) \mathrm{ppm} .{ }^{13} \mathrm{C} \mathrm{NMR}\left(126 \mathrm{MHz}, \mathrm{CDCl}_{3}\right) \delta 137.49,130.17,128.48$, 125.99, 101.18, 98.16, 82.23, 81.21, 78.73, 69.71, 62.71, 62.40, 61.25, 55.47, 40.24, 39.90, $31.55,30.32,30.21,29.14,28.89,23.58,23.45,23.10,22.88,14.13,14.10,13.95,11.02,10.96$ ppm. FT-IR (ATR) 2954, 2924, 2870, 1458, 1373, 1265, 1103, 1049, 910, $710 \mathrm{~cm}^{-1}$.

b. To a solution of $1 \mathbf{a}(0.44 \mathrm{~g})$ in methanol, $1 \mathrm{~g}$ of Amberlyst H-from resin was added. After stirring for $12 \mathrm{~h}$ under ambient condition at room temperature, the mixture was filtered over celite. The obtained solution was concentrated under reduced pressure and purified by column 
chromatography (gradient ethyl acetate/hexanes) to afford $\mathbf{1 b}$ as a colorless liquid (yield: 0.22 g). ${ }^{1} \mathrm{H}$ NMR (400 MHz, $\left.\mathrm{CDCl}_{3}\right) \delta 4.84(\mathrm{dd}, J=4,1 \mathrm{~Hz}, 1 \mathrm{H}), 3.90(\mathrm{~m}, 2 \mathrm{H}), 3.81(\mathrm{~m}, 1 \mathrm{H}), 3.68$ (dt, $J=8,4 \mathrm{~Hz}, 1 \mathrm{H}), 3.59-3.37(\mathrm{~m}, 4 \mathrm{H}), 3.45(\mathrm{~s}, 3 \mathrm{H}), 3.34-3.25(\mathrm{~m}, 1 \mathrm{H}), 2.47-2.41(\mathrm{~m}$, $1 \mathrm{H}), 1.97(\mathrm{dd}, J=7,6 \mathrm{~Hz}, 1 \mathrm{H}), 1.52(\mathrm{~m}, 2 \mathrm{H}), 1.50-1.39(\mathrm{~m}, 1 \mathrm{H}), 1.42-1.29(\mathrm{~m}, 5 \mathrm{H}), 1.29$ (m, 8H), $0.96-0.85(\mathrm{~m}, 11 \mathrm{H}) \mathrm{ppm} .{ }^{13} \mathrm{C} \mathrm{NMR}\left(101 \mathrm{MHz}, \mathrm{CDCl}_{3}\right) \delta$ 98.19, 81.35, 80.95, 73.45, $70.91,70.80,62.87,55.42,40.59,40.47,40.08,30.58,30.50,30.42$, 29.36, 29.30, 29.18, 29.12, 23.93, 23.75, 23.59, 23.28, 23.26, 23.24, 14.29, 14.26, 14.24, 11.34, 11.10, 11.08, 11.04 ppm. FT-IR (ATR) 3410, 2955, 2924, 2870, 1458, 1366, 1234, 1111, 1057, 902, $709 \mathrm{~cm}^{-1}$.

c. To a solution of $1 \mathbf{b}(0.22 \mathrm{~g}, 0.53 \mu \mathrm{mol})$ in anhydrous DCM in a $100 \mathrm{~mL}$ two-neck round bottom flask, pyridine $(0.13 \mathrm{~g}, 1.6 \mu \mathrm{mol})$ was added. Triphosgene $(0.11 \mathrm{~g}, 0.37 \mu \mathrm{mol})$ dissolved in anhydrous DCM was added dropwise via a syringe over $10 \mathrm{~min}$. The reaction mixture was allowed to stir at $35{ }^{\circ} \mathrm{C}$ for $10 \mathrm{~h}$ under $\mathrm{N}_{2(\mathrm{~g})}$ flow, followed by quenching with addition of $\mathrm{NaHCO}_{3(\mathrm{aq})}$ slowly. The organic layer was concentrated under reduced pressure and the product was purified by column chromatography (gradient acetone/DCM) to afford 1c methyl2,3-O-2-ethylhexyl-4,6- $O$-carbonyl- $\alpha$-D-glucopyranoside $\mathbf{G C}\left(\mathbf{E H E}^{2}\right)$ (yield: $0.16 \mathrm{~g}$ ) as a colorless liquid. ${ }^{1} \mathrm{H}$ NMR $\left(500 \mathrm{MHz}, \mathrm{CDCl}_{3}\right) \delta 4.82(\mathrm{~d}, J=3.5 \mathrm{~Hz}, 1 \mathrm{H}), 4.46(\mathrm{dd}, J=10,6$ $\mathrm{Hz}, 1 \mathrm{H}), 4.19$ (t, $J=10 \mathrm{~Hz}, 1 \mathrm{H}), 4.10-3.94(\mathrm{~m}, 2 \mathrm{H}), 3.75-3.59$ (m, 3H), $3.59-3.50$ (m, 1H), $3.46(\mathrm{~s}, 3 \mathrm{H}), 3.29$ (dd, $J=9,4 \mathrm{~Hz}, 1 \mathrm{H}), 1.55-1.45(\mathrm{~m}, 2 \mathrm{H}), 1.45-1.19(\mathrm{~m}, 16 \mathrm{H}), 1.01$ - $0.72(\mathrm{~m}, 12 \mathrm{H}) \mathrm{ppm} .{ }^{13} \mathrm{C} \mathrm{NMR}\left(126 \mathrm{MHz}, \mathrm{CDCl}_{3}\right) \delta 147.62,99.30,79.99,79.93,77.79$, 77.77, 76.55, 76.53, 75.04, 75.02, 69.75, 59.76, 56.20, 53.56, 40.45, 40.40, 40.07, 40.01, 30.54, $30.47,30.40,30.33,29.34,29.29,29.17,29.12,23.80,23.72,23.66,23.57,23.25,14.25,11.26$, 11.15, 11.06, 11.01 ppm. FT-IR (ATR) 2962, 2932, 2870, 1751, 1458, 1396, 1273, 1165, 1141, $979,787,574 \mathrm{~cm}^{-1}$.

\section{Polymerization of GC(EHE $\left.{ }^{2}\right)$}

A solution of $\mathrm{GC}\left(\mathrm{EHE}^{2}\right)$ monomer $(49.5 \mathrm{mg})$ and 4-methylbenzyl alcohol $(0.26 \mathrm{mg}, 1.0 \mathrm{mg} / \mathrm{mL}$ in DCM, $0.10 \mathrm{~mL}$ ) were prepared in a glovebox in a vial equipped with a stir bar at $30{ }^{\circ} \mathrm{C}$. A solution of TBD $(3.2 \mathrm{mg} / \mathrm{mL}$ in DCM, $0.05 \mathrm{~mL})$ was injected to the reaction mixture, and the reaction was allowed to stir at $30{ }^{\circ} \mathrm{C}$ for $6.5 \mathrm{~h}$, followed by quenching by adding an aliquot of acetic acid solution. The product was purified by precipitation into methanol three times and dried 
under vacuum to afford the polymer as a white solid $(20 \mathrm{mg}) .{ }^{1} \mathrm{H}$ NMR (500 MHz, $\left.\mathrm{CDCl}_{3}\right) \delta 4.76$ $(\mathrm{d}, J=8 \mathrm{~Hz}), 4.57(\mathrm{~m}), 4.41-4.21(\mathrm{~m}), 4.14(\mathrm{br}), 3.95-3.79(\mathrm{~m}), 3.68(\mathrm{br}), 3.52-3.33(\mathrm{~m}), 3.33$ - $3.22(\mathrm{~m}), 2.34(\mathrm{~s}), 0.96$ - 0.71 (m) ppm. ${ }^{13} \mathrm{C} \mathrm{NMR}\left(126 \mathrm{MHz}, \mathrm{CDCl}_{3}\right) \delta$ 154.43, 97.69, 97.49, 80.61, 78.95, 78.55, 75.76, 75.19, 67.43, 67.10, 55.49, 40.46, 40.34, 40.01, 30.52, 30.42, 30.31, 29.28, 29.12, 23.68, 23.51, 23.25, 14.30, 14.26, 11.30, 11.09, 11.00, 10.86 ppm. FT-IR (ATR): 2954, 2924, 2870, 1743, 1458, 1381, 1257, 1103, 1049, 964, 848, 795, 756, $671 \mathrm{~cm}^{-1}$. SEC (THF, $1 \mathrm{~mL} / \mathrm{min}$, polystyrene standards): $12.3 \mathrm{kDa}, Ð=1.16 . T_{\mathrm{g}}=98{ }^{\circ} \mathrm{C}$. TGA in $\mathrm{N}_{2(\mathrm{~g})}: 230-280{ }^{\circ} \mathrm{C}$, $98 \%$ mass loss.

\section{Oligomerization of $\mathrm{GC}\left(\mathrm{EHE}^{2}\right)$ and isolation of the unimers and dimers}

A solution of $\mathrm{GC}\left(\mathrm{EHE}^{2}\right)$ monomer (105 mg, 1 eq.) and 4-methylbenzyl alcohol (46 mg, 1.5 eq.) were dissolved in $1 \mathrm{~mL}$ of DCM in a vial equipped with a stir bar in a glovebox at $30{ }^{\circ} \mathrm{C}$. A solution of TBD (13 mg/mL in DCM, $0.05 \mathrm{~mL})$ was injected to the reaction mixture, and the reaction was allowed to stir at $30{ }^{\circ} \mathrm{C}$ for $1.5 \mathrm{~h}$, followed by quenching by adding an aliquot of acetic acid solution. The product was purified and fractionated by preparative SEC to afford

mixtures of unimers and dimers. The two regioisomeric unimers were then separated by preparative thin layer chromatography (ethyl acetate/hexanes) and determined using 1D and 2D NMR spectroscopies. The dimer mixture was directly used for further characterization.

GC(EHE $\left.{ }^{2}\right)$ unimer isomer I: ${ }^{1} \mathrm{H}$ NMR $\left(400 \mathrm{MHz}, \mathrm{CDCl}_{3}\right) \delta 7.28(\mathrm{~d}, J=8 \mathrm{~Hz}, 2 \mathrm{H}), 7.16(\mathrm{~d}, J=$ $8 \mathrm{~Hz}, 2 \mathrm{H}), 5.13(\mathrm{~s}, 2 \mathrm{H}), 4.79(\mathrm{~d}, J=3 \mathrm{~Hz}, 1 \mathrm{H}), 4.40$ (d, J = 4 Hz, 2H), $3.91-3.80(\mathrm{~m}, 1 \mathrm{H}), 3.80$ - 3.73 (m, 1H), $3.58-3.31(\mathrm{~m}, 8 \mathrm{H}), 3.27$ (dd, J = 9, $3 \mathrm{~Hz}, 1 \mathrm{H}), 2.45$ (s, 1H), 2.35 (s, 3H), 1.49 (m, $2 \mathrm{H}), 1.45-1.17(\mathrm{~m}, 19 \mathrm{H}), 0.96-0.78(\mathrm{~m}, 12 \mathrm{H}) \mathrm{ppm} .{ }^{13} \mathrm{C} \mathrm{NMR}\left(126 \mathrm{MHz}, \mathrm{CDCl}_{3}\right) \delta 155.50$, 138.59, 132.30, 129.37, 128.74, 98.13, 81.28, 80.76, 80.75, 80.67, 80.66, 76.74, 76.58, 75.40, 73.57, 73.54, 70.03, 69.90, 69.21, 66.92, 55.46, 40.57, 40.46, 40.04, 40.01, 30.66, 30.65, 30.56, $30.46,30.39,29.85,29.81,29.51,29.35,29.29,29.16,29.13,23.90,23.88,23.71,23.56,23.28$, 23.26, 23.24, 21.37, 14.28, 14.26, 14.25, 11.33, 11.31, 11.09, 11.06, 11.05 ppm. FT-IR (ATR) 3471, 2970, 2916, 2831, 1751, 1373, 1242, 1149, 1087, 1041, 964, 910, 787, $748 \mathrm{~cm}^{-1}$. HRMS $\left(\mathrm{ESI}^{+}\right): \mathrm{C}_{32} \mathrm{H}_{54} \mathrm{O}_{8}, 589.3711$ found $\left(\mathrm{M}+\mathrm{Na}^{+}\right)$589.3700; $\mathrm{C}_{32} \mathrm{H}_{54} \mathrm{O}_{8} \mathrm{NH}_{4}{ }^{+}$584.4157, found 584.4149. 
GC(EHE $\left.{ }^{2}\right)$ unimer isomer II: ${ }^{1} \mathrm{H}$ NMR $\left(400 \mathrm{MHz}, \mathrm{CDCl}_{3}\right) \delta 7.17(\mathrm{~d}, J=8 \mathrm{~Hz}, 2 \mathrm{H}), 5.13(\mathrm{~m}$, 2H), $4.82(\mathrm{~d}, J=3 \mathrm{~Hz}, 1 \mathrm{H}), 4.70(\mathrm{t}, J=10 \mathrm{~Hz}, 1 \mathrm{H}), 3.82-3.35(\mathrm{~m}, 11 \mathrm{H}), 3.33(\mathrm{dd}, J=9,4 \mathrm{~Hz}$, $1 \mathrm{H}), 2.35(\mathrm{~s}, 3 \mathrm{H}), 1.45-1.12(\mathrm{~m}, 16 \mathrm{H}), 0.96-0.72(\mathrm{~m}, 12 \mathrm{H}) \mathrm{ppm} .{ }^{13} \mathrm{C} \mathrm{NMR}\left(126 \mathrm{MHz}, \mathrm{CDCl}_{3}\right)$ : $\delta 155.63,138.77,131.97,129.47,128.71,128.69,98.22,80.78,80.69,78.73,76.59,74.82,74.30$, 70.38, 69.53, 61.33, 55.55, 40.49, 40.29, 40.03, 30.59, 30.42, 30.36, 30.24, 29.85, 29.30, 29.25, $29.15,23.70,23.60,23.55,23.26,23.23,21.37,14.27,11.24,11.09,11.05$ ppm. FT-IR (ATR) 3433, 2946, 2924, 2862, 1751, 1465, 1381, 1258, 1104, 1042, 964, $810 \mathrm{~cm}^{-1}$. HRMS (ESI $)$ $\mathrm{C}_{32} \mathrm{H}_{54} \mathrm{O}_{8}, 589.3711$, found $\left(\mathrm{M}+\mathrm{Na}^{+}\right)$589.3699; $\mathrm{C}_{32} \mathrm{H}_{54} \mathrm{O}_{8} \mathrm{NH}_{4}{ }^{+}$584.4157, found 584.4148.

\section{Oligomerization of GC(OMe) and separation of GC(OMe) oligomers}

A solution of $\mathrm{GC}(\mathrm{OMe})$ monomer (300 mg, 3 eq.) and 4-methylbenzyl alcohol (49 mg, 1 eq.) were dissolved in $1 \mathrm{~mL}$ of DCM in a vial equipped with a stir bar in a glovebox at $30{ }^{\circ} \mathrm{C}$. A solution of TBD (34 mg/mL in DCM, $0.1 \mathrm{~mL})$ was injected to the reaction mixture, and the reaction was allowed to stir at $30{ }^{\circ} \mathrm{C}$ for $30 \mathrm{~min}$, followed by quenching by adding an aliquot of acetic acid solution. The product was purified and fractionated by preparative SEC to afford mixtures of regioisomeric unimers and dimers. The mixtures were directly used for further characterization. 


\section{Figures}

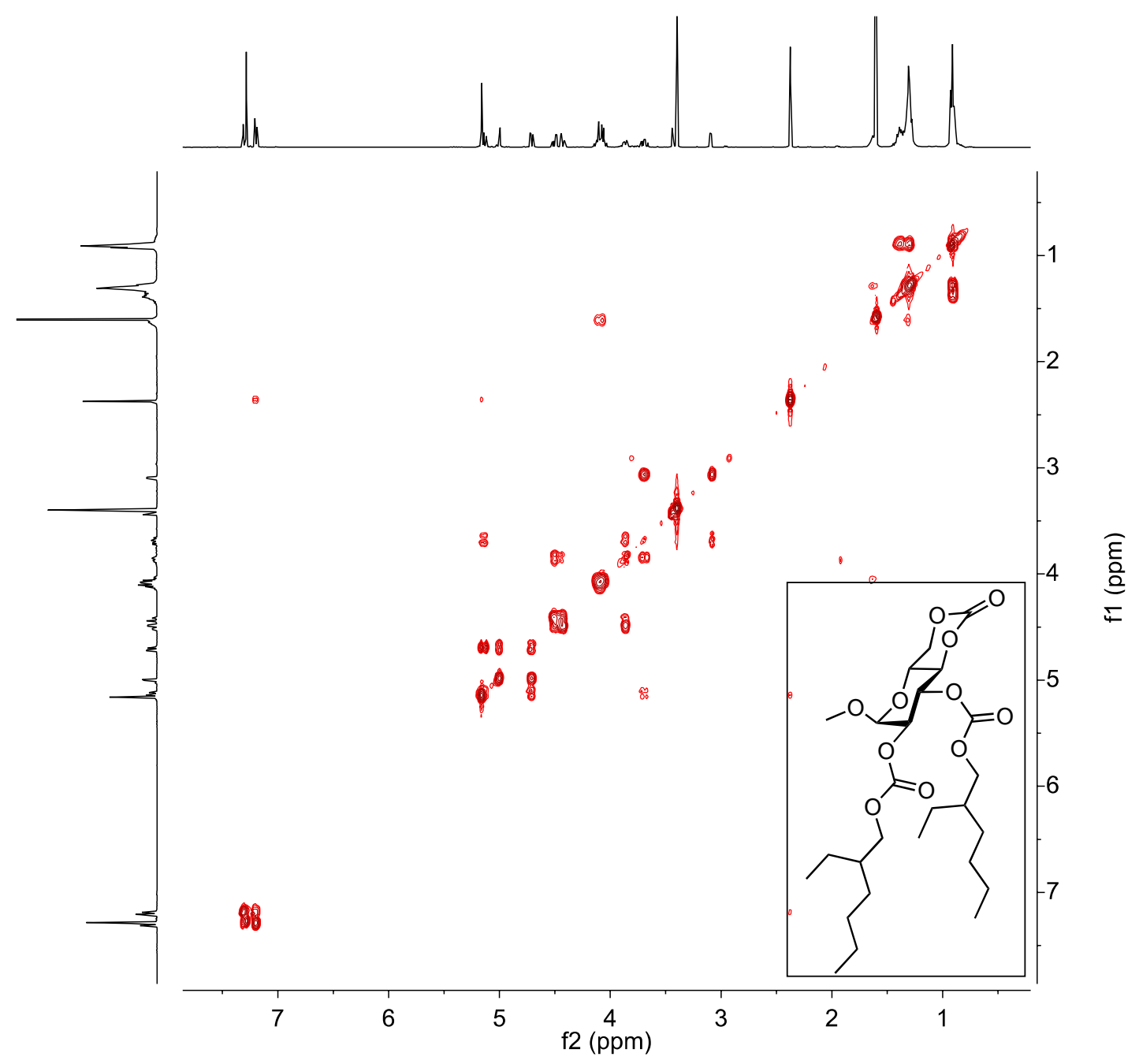

Figure S1. A full view of COSY spectrum (500 MHz) of $\mathrm{GC}\left(\mathrm{EHC}^{2}\right)$ unimer in $\mathrm{CDCl}_{3}$. 

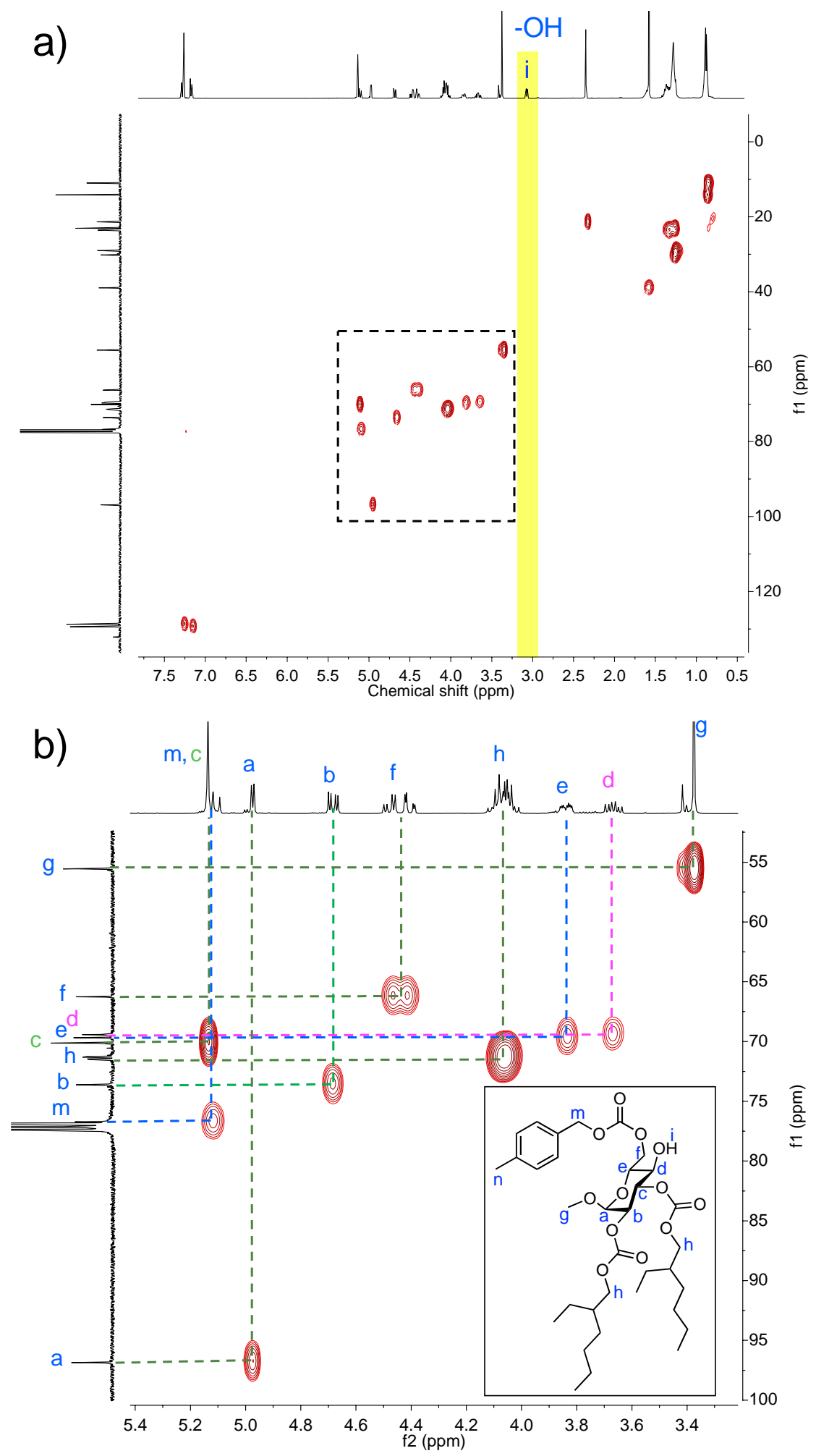

Figure S2. HSQC spectra (500 MHz for $\left.{ }^{1} \mathrm{H}\right)$ of $\mathrm{GC}\left(\mathrm{EHC}^{2}\right)$ unimer in $\mathrm{CDCl}_{3}$. (a) Full spectrum, and (b) zoomed in spectrum of the boxed area in (a). 


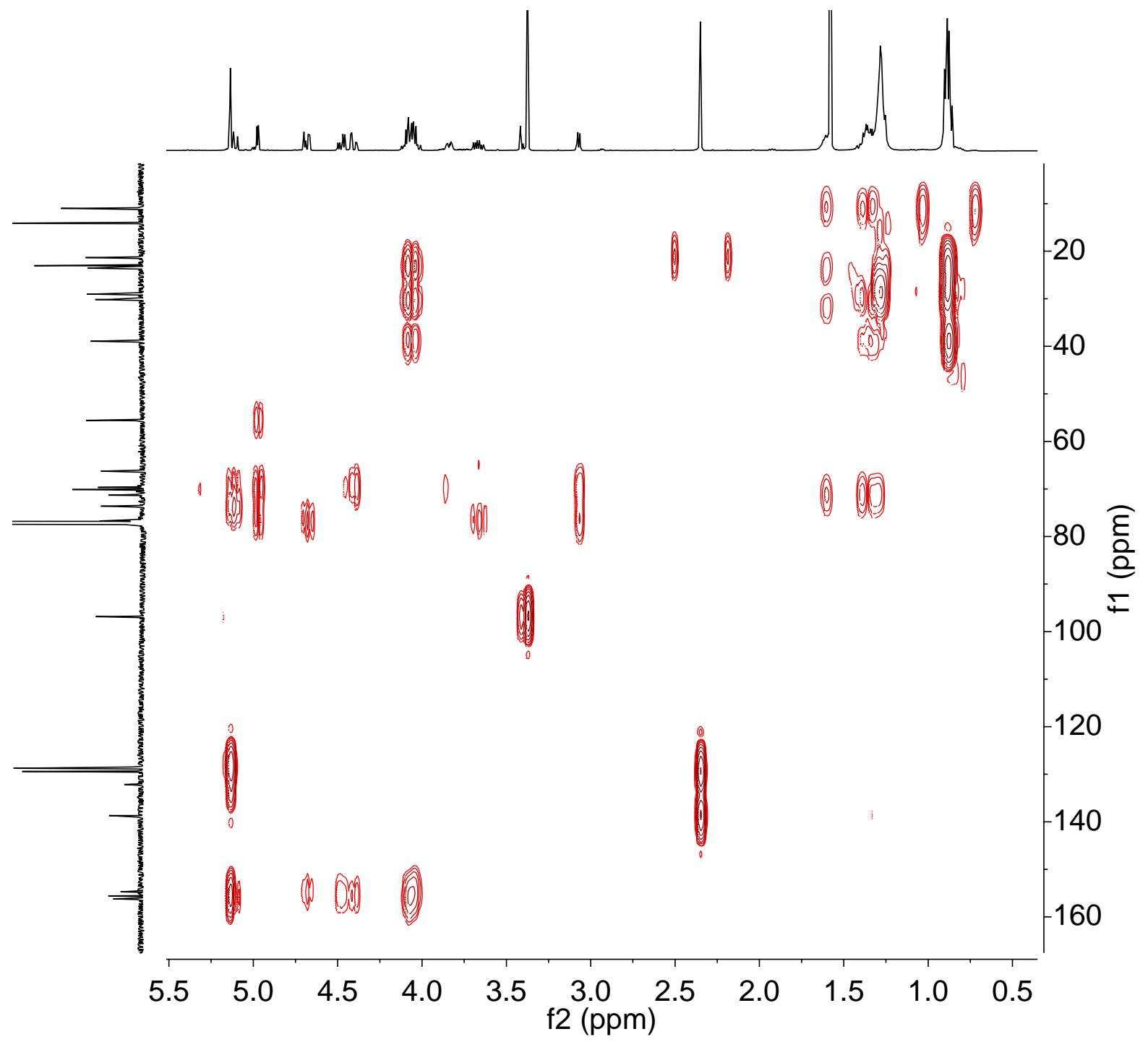

Figure S3. HMBC full spectrum (400 MHz for $\left.{ }^{1} \mathrm{H}\right)$ of $\mathrm{GC}\left(\mathrm{EHC}^{2}\right)$ unimer in $\mathrm{CDCl}_{3}$. 


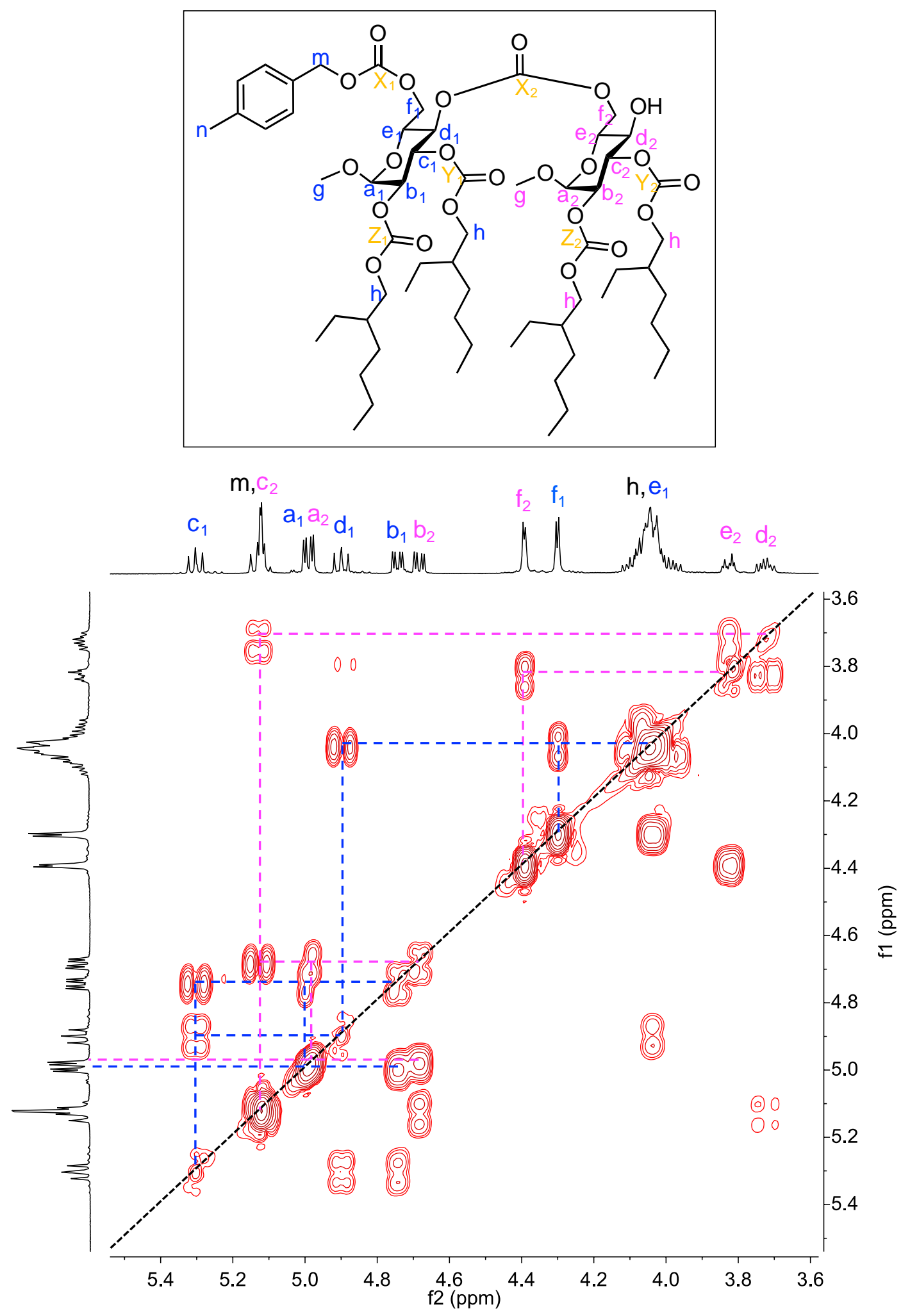

Figure S4. COSY spectrum (500 $\mathrm{MHz}$ for $\left.{ }^{1} \mathrm{H}\right)$ of $\mathrm{GC}\left(\mathrm{EHC}^{2}\right)$ dimer in $\mathrm{CDCl}_{3}$. 


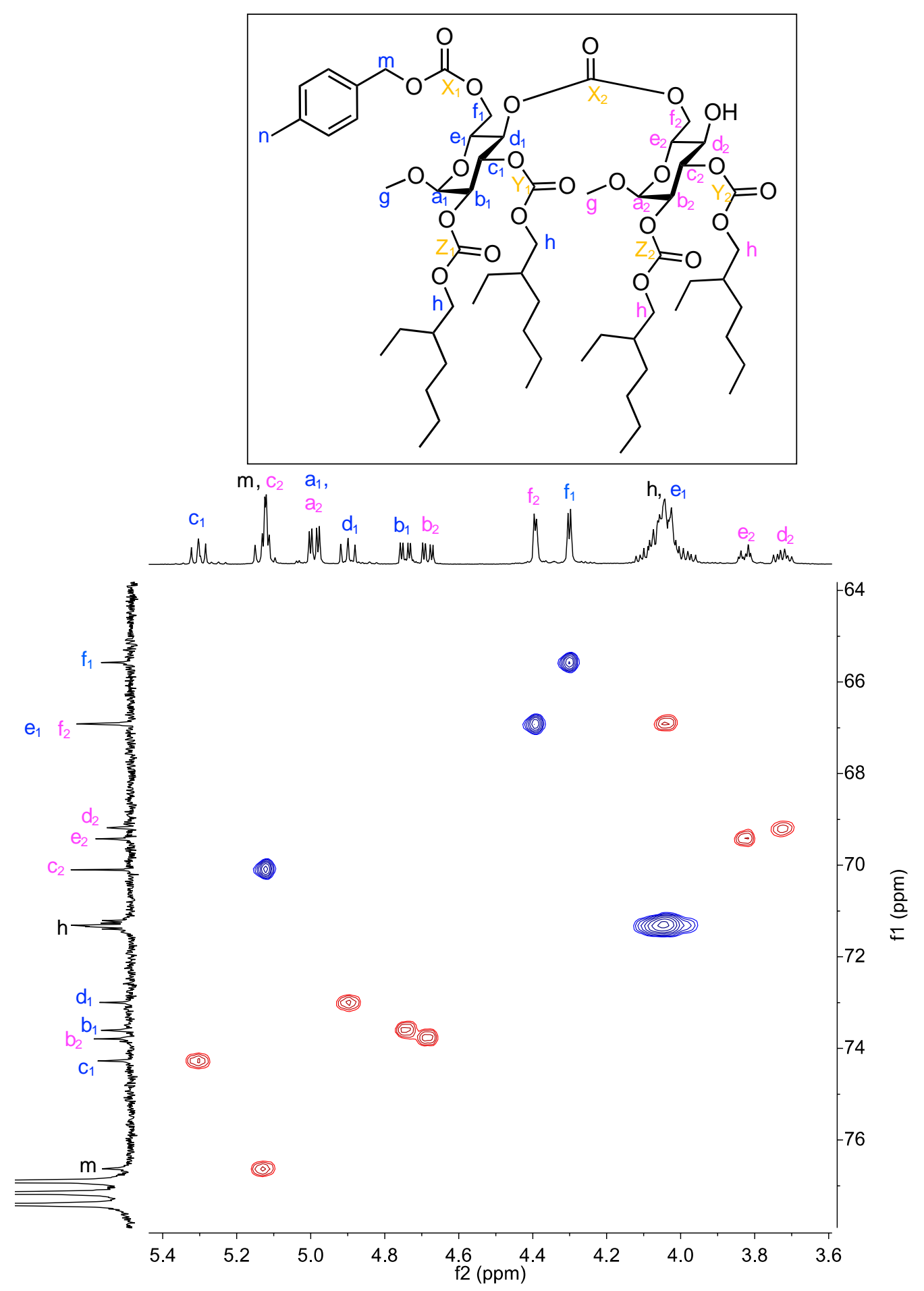

Figure S5. HSQC spectrum $\left(500 \mathrm{MHz}\right.$ for $\left.{ }^{1} \mathrm{H}\right)$ of $\mathrm{GC}\left(\mathrm{EHC}^{2}\right)$ dimer in $\mathrm{CDCl}_{3}$. 


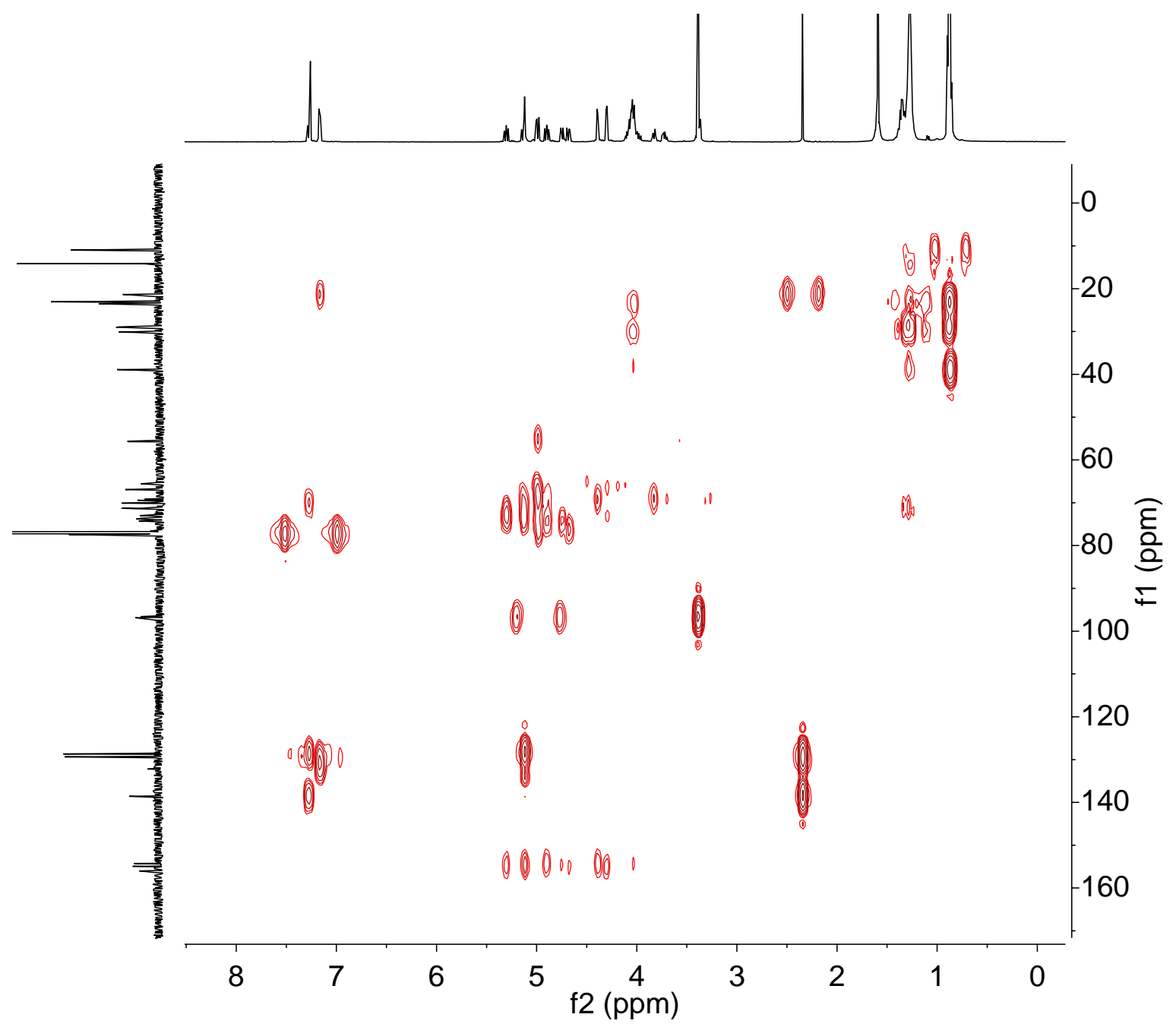

Figure S6. $\mathrm{HMBC}$ spectrum $\left(400 \mathrm{MHz}\right.$ for $\left.{ }^{1} \mathrm{H}\right)$ of $\mathrm{GC}\left(\mathrm{EHC}^{2}\right)$ dimer in $\mathrm{CDCl}_{3}$. 

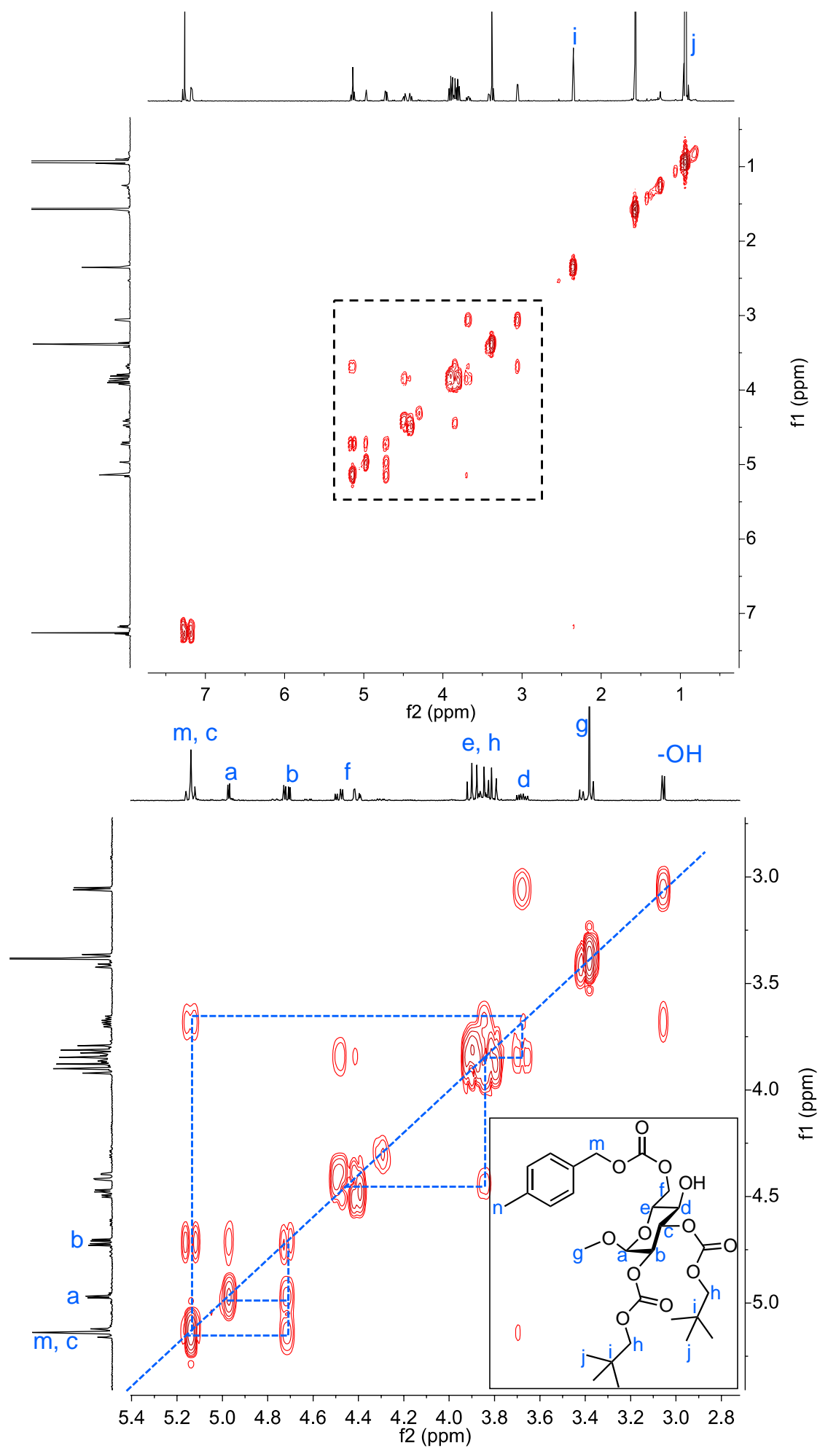

Figure S7. COSY spectra $(500 \mathrm{MHz})$ of $\mathrm{GC}\left(\right.$ neoPC $\left.{ }^{2}\right)$ unimer in $\mathrm{CDCl}_{3}$. (a) Full spectrum, and (b) zoomed in of the boxed area in (a). 

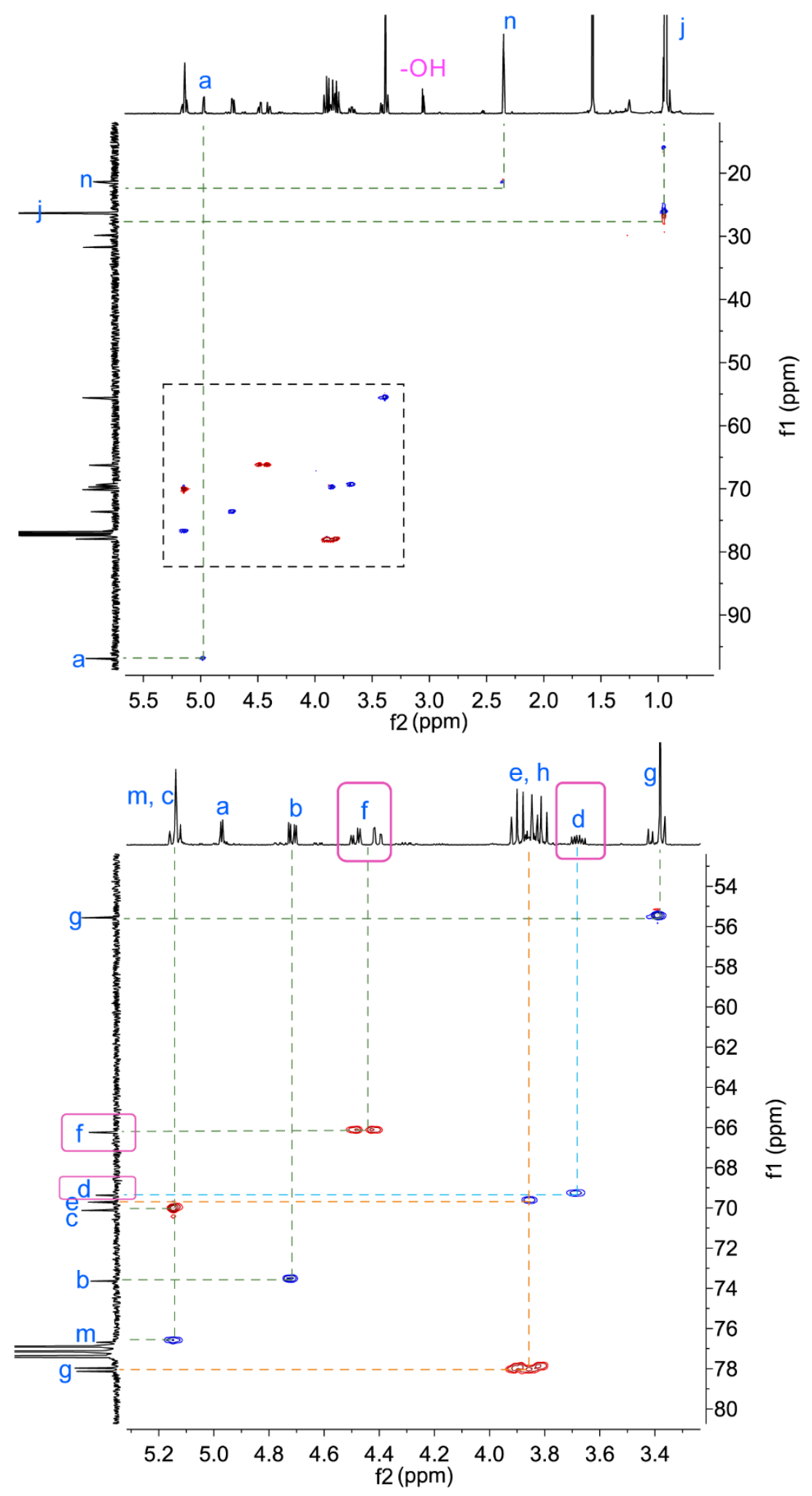

Figure S8. HSQC spectra $\left(500 \mathrm{MHz}\right.$ for $\left.{ }^{1} \mathrm{H}\right)$ of $\mathrm{GC}\left(\right.$ neoPC $\left.{ }^{2}\right)$ unimer in $\mathrm{CDCl}_{3}$. 


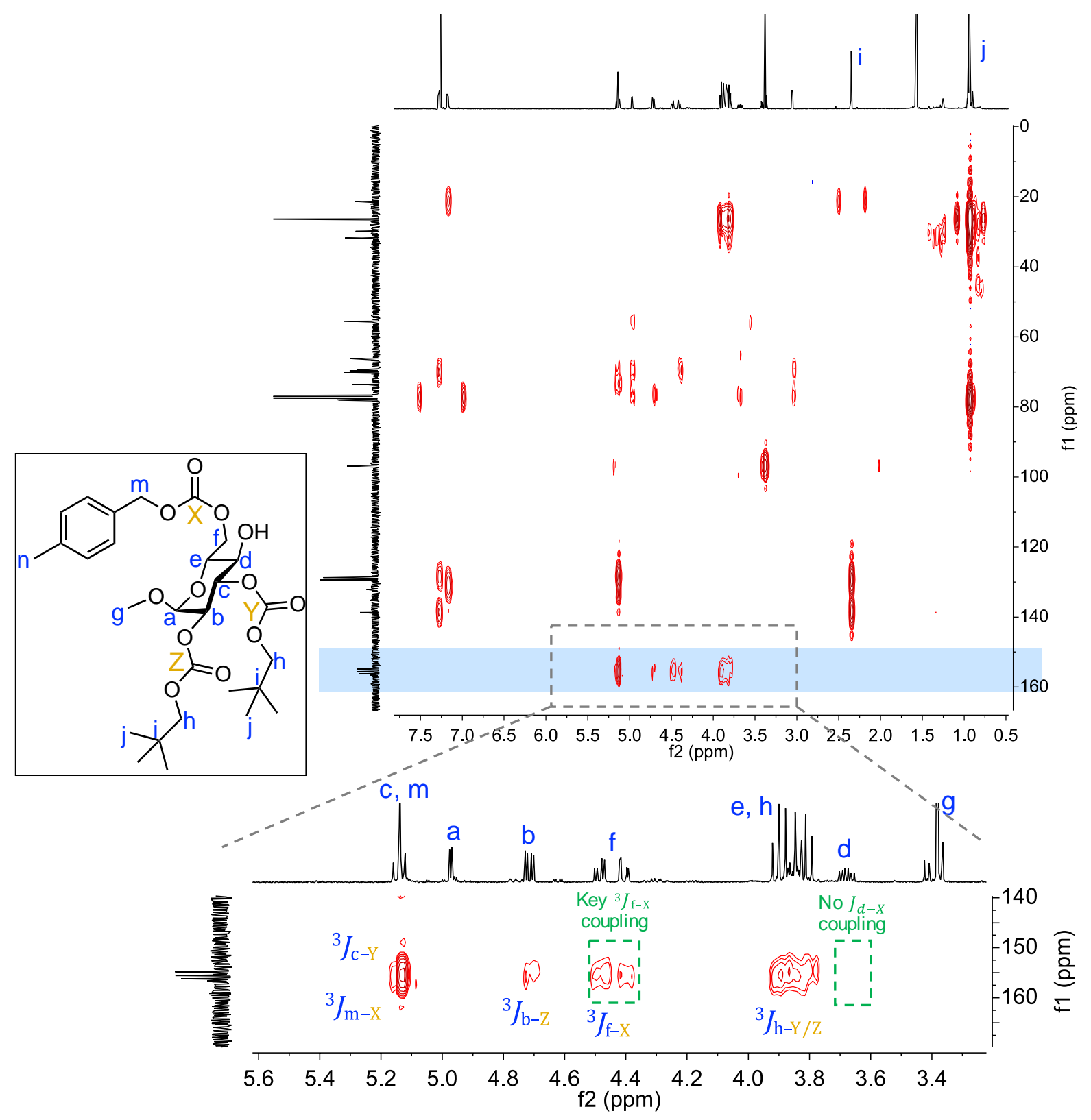

Figure S9. $\mathrm{HMBC}$ spectra $\left(400 \mathrm{MHz}\right.$ for $\left.{ }^{1} \mathrm{H}\right)$ of $\mathrm{GC}\left(\right.$ neoPC $\left.{ }^{2}\right)$ unimer in $\mathrm{CDCl}_{3}$. 


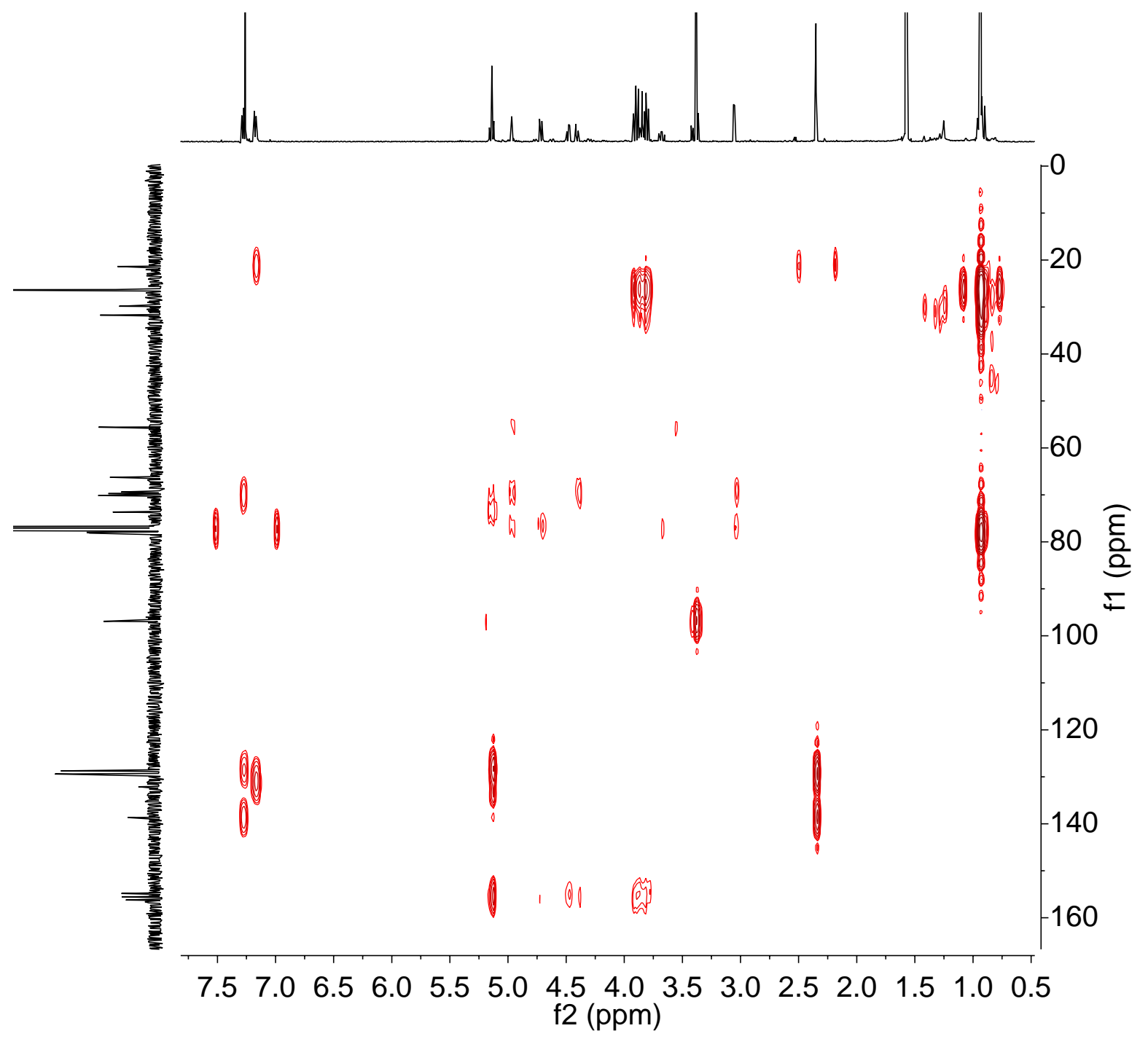

Figure S10. $\mathrm{HMBC}$ spectrum $\left(400 \mathrm{MHz}\right.$ for $\left.{ }^{1} \mathrm{H}\right)$ of $\mathrm{GC}\left(\right.$ neoPC $\left.{ }^{2}\right)$ unimer in $\mathrm{CDCl}_{3}$. 


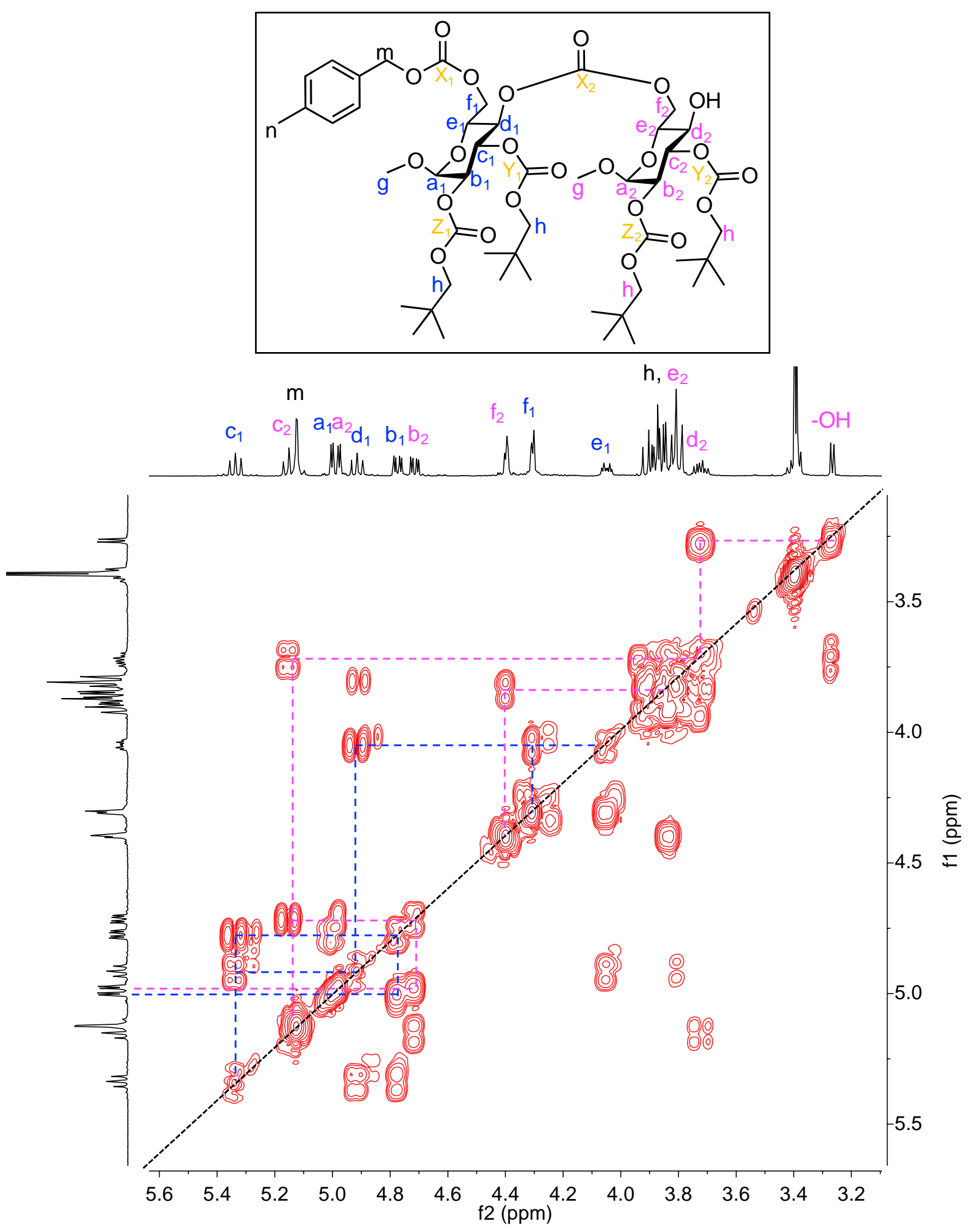

Figure S11. COSY spectrum $\left(500 \mathrm{MHz}\right.$ for $\left.{ }^{1} \mathrm{H}\right)$ of $\mathrm{GC}\left(\right.$ neoPC $\left.{ }^{2}\right)$ dimer in $\mathrm{CDCl}_{3}$. 


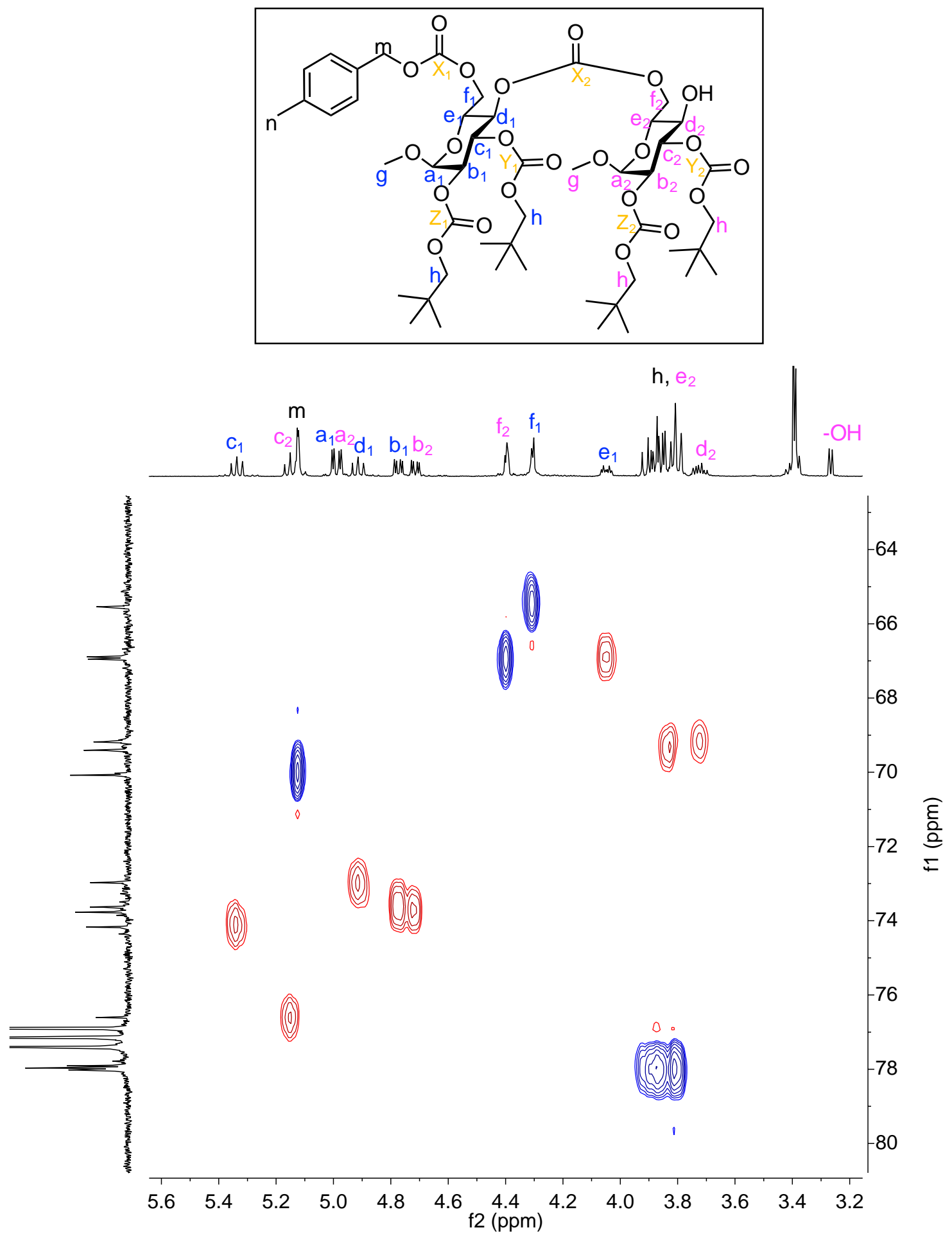

Figure S12. HSQC spectrum (500 $\mathrm{MHz}$ for $\left.{ }^{1} \mathrm{H}\right)$ of $\mathrm{GC}\left(\right.$ neoPC $\left.{ }^{2}\right)$ dimer in $\mathrm{CDCl}_{3}$. 


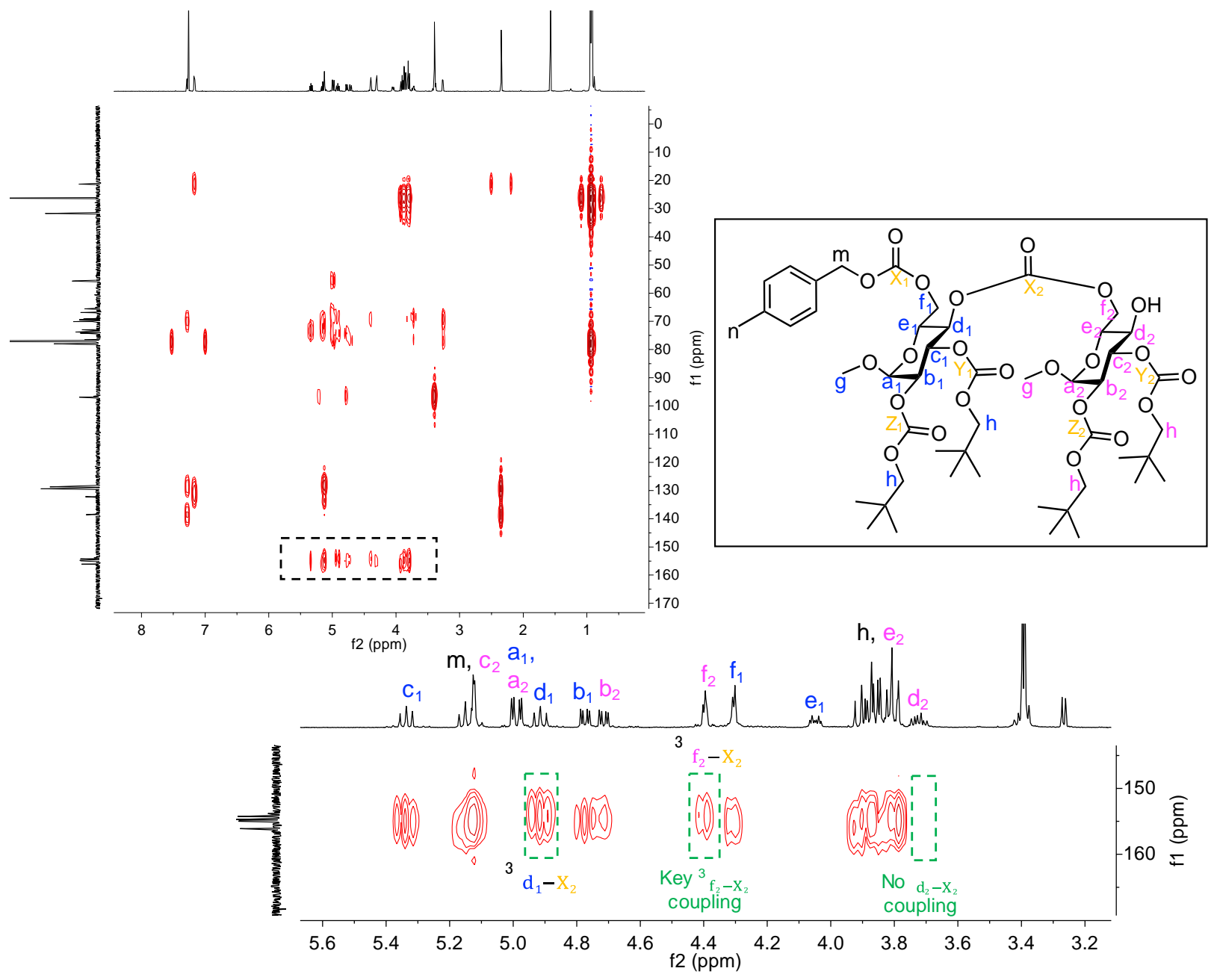

Figure S13. $\mathrm{HMBC}$ spectra $\left(500 \mathrm{MHz}\right.$ for $\left.{ }^{1} \mathrm{H}\right)$ of $\mathrm{GC}\left(\right.$ neoPC $\left.{ }^{2}\right)$ dimer in $\mathrm{CDCl}_{3}$. 


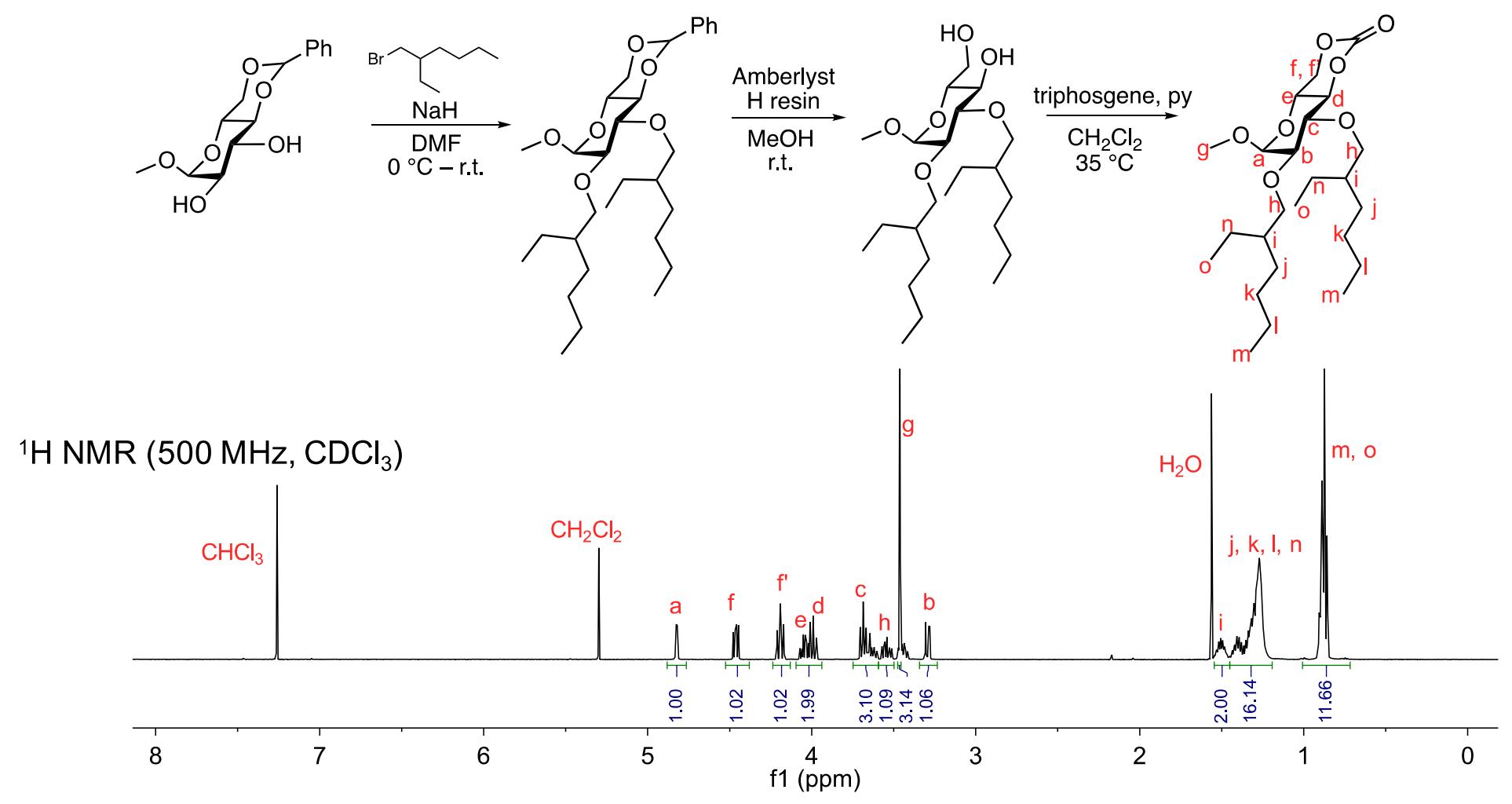

${ }^{13} \mathrm{C} \mathrm{NMR}\left(126 \mathrm{MHz}, \mathrm{CDCl}_{3}\right)$

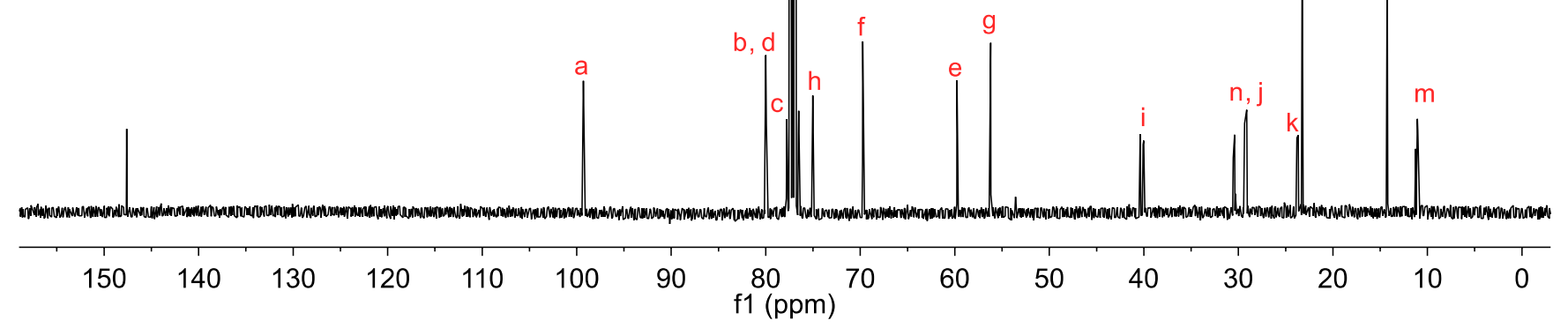

Figure S14. ${ }^{1} \mathrm{H}(500 \mathrm{MHz}) \&{ }^{13} \mathrm{C}(126 \mathrm{MHz}) \mathrm{NMR}$ spectra of $\mathrm{GC}\left(\mathrm{EHE}^{2}\right)$ monomer in $\mathrm{CDCl}_{3}$. 


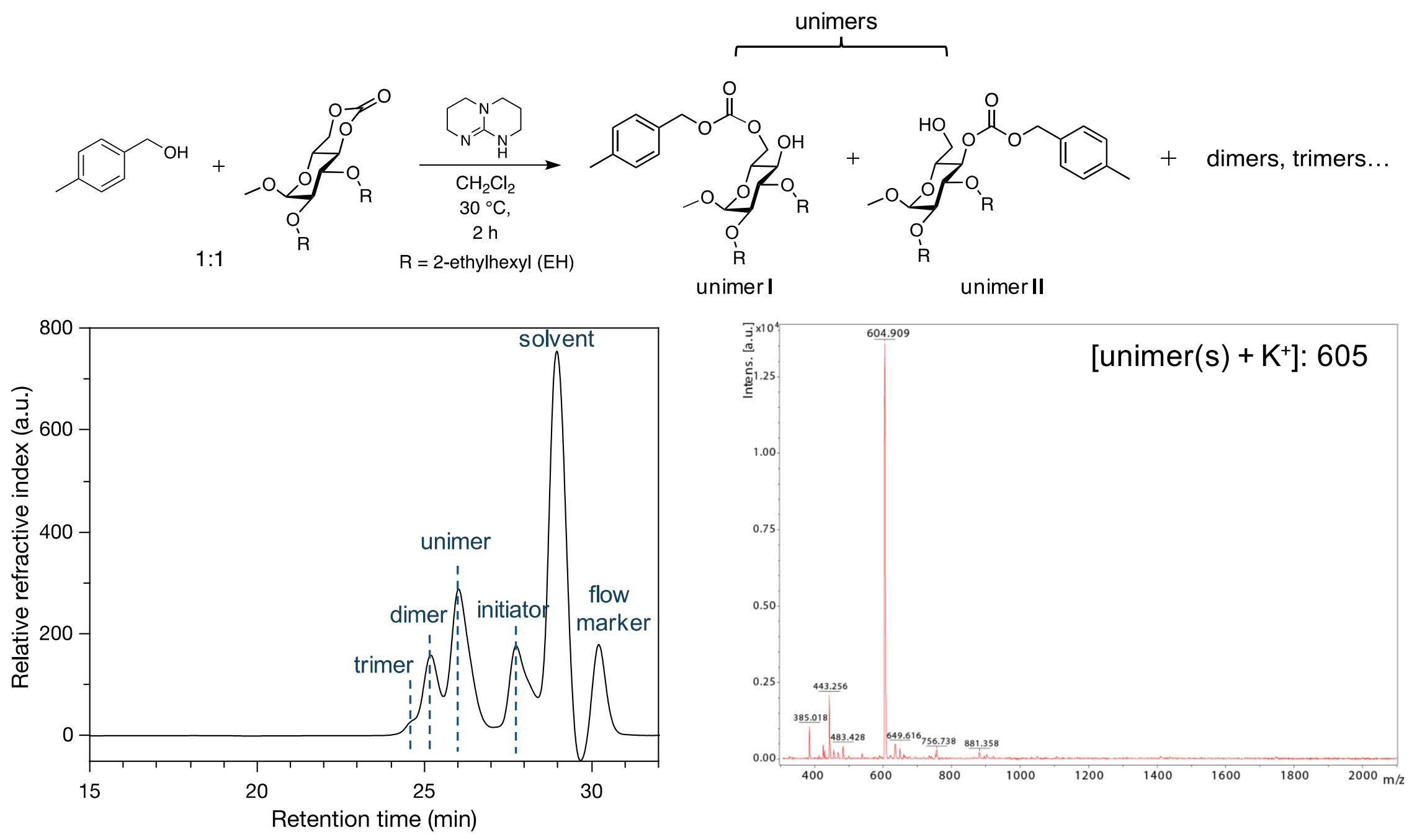

Figure S15. SEC trace of the oligomer mixture and MALDI-TOF spectrum of isolated unimers of GC(EHE $\left.{ }^{2}\right)$. 

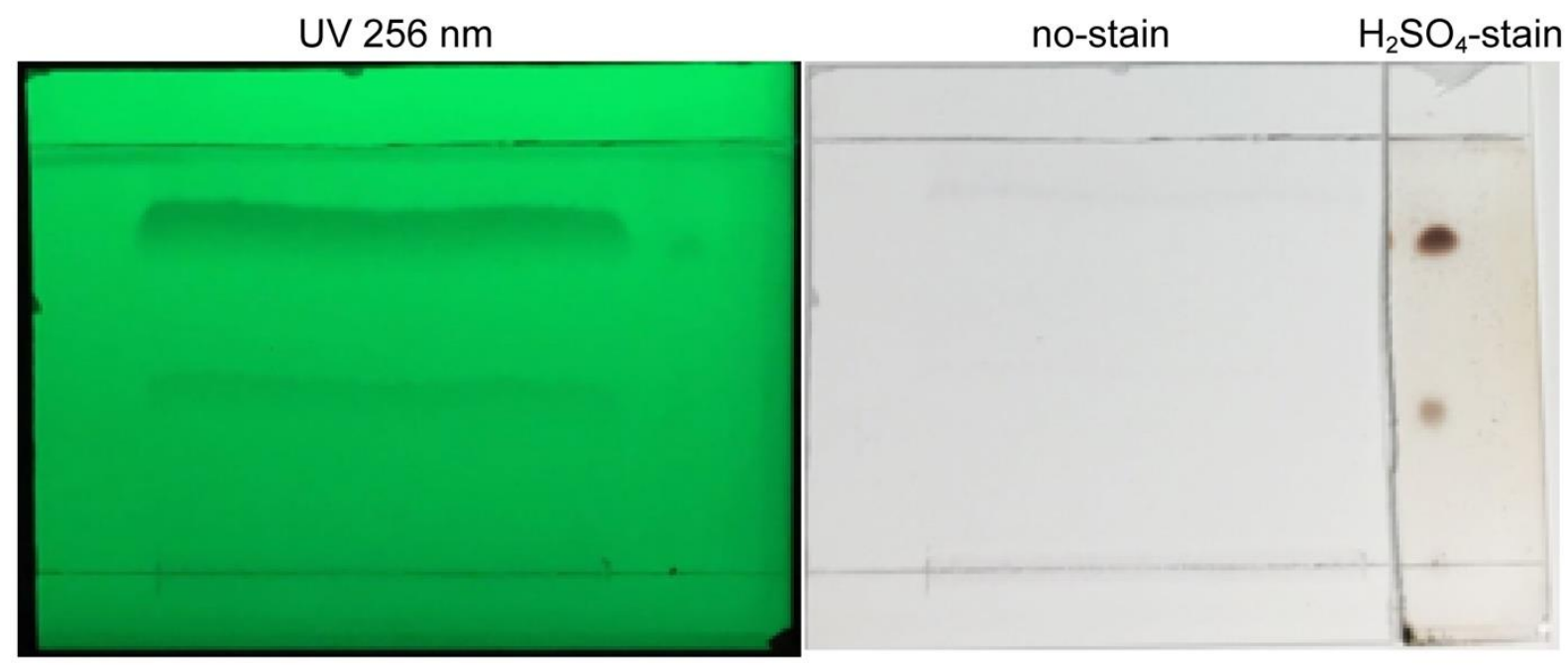

Figure S16. TLC plate images of the regioisomeric unimers of $\mathrm{GC}\left(\mathrm{EHE}^{2}\right)$ after separation in $20 \%$ ethyl acetate $/ 80 \%$ hexanes (top fraction: $C-O 4$ cleavage product, isomer $\mathbf{I}, \mathrm{Rf}=0.79$; bottom fraction: $C-O 6$ cleavage product, isomer $\mathbf{I I}, \mathrm{Rf}=0.40$ ). 




Figure S17. ${ }^{1} \mathrm{H}$ NMR, COSY and $\mathrm{HSQC}$ spectra of $\mathrm{GC}\left(\mathrm{EHE}^{2}\right)$ unimer regioisomer $\mathbf{I}$ in $\mathrm{CDCl}_{3}$. 

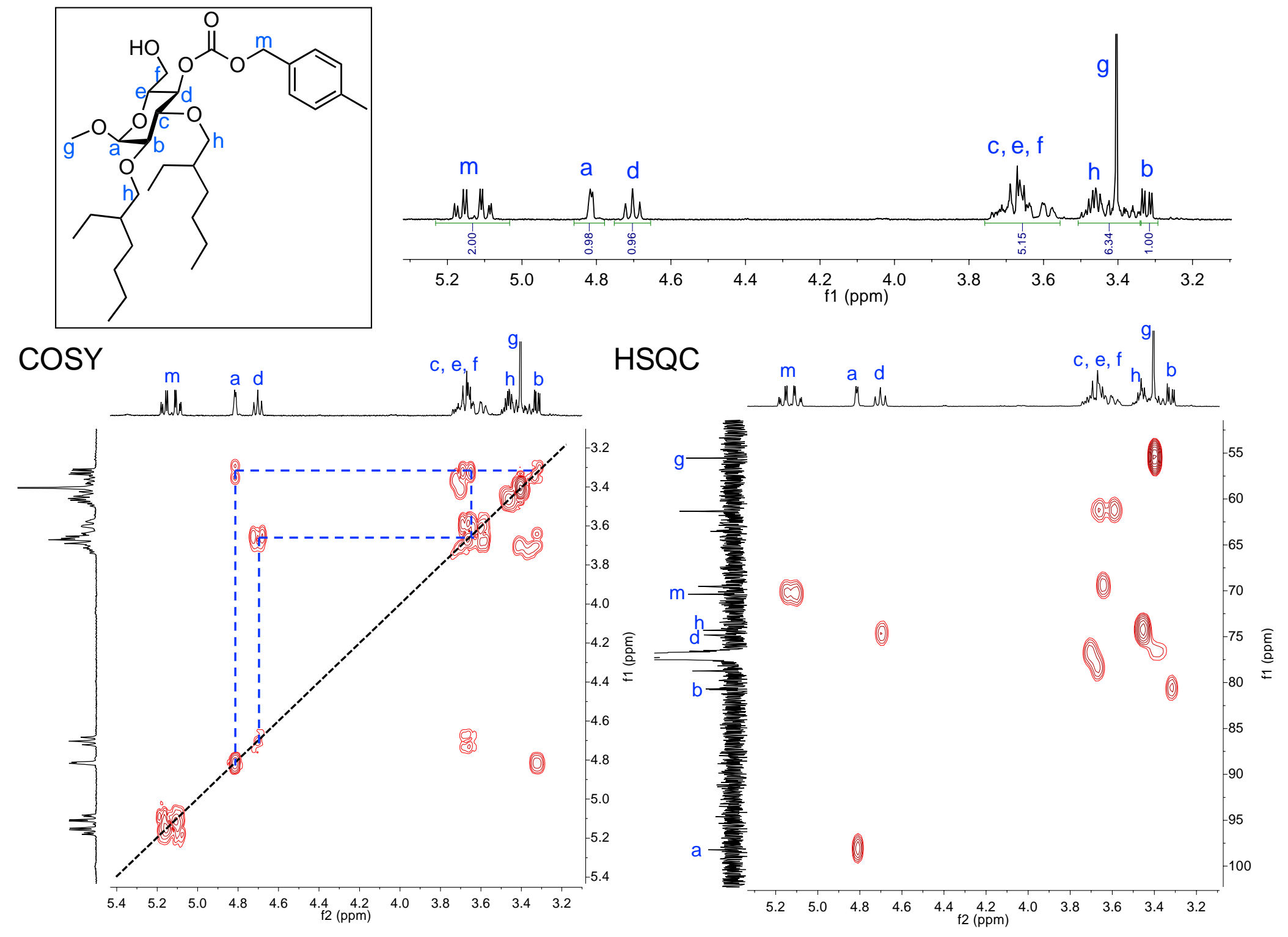

Figure S18. ${ }^{1} \mathrm{H}$ NMR, COSY and HSQC spectra of $\mathrm{GC}\left(\mathrm{EHE}^{2}\right)$ unimer regioisomer II in $\mathrm{CDCl}_{3}$. 


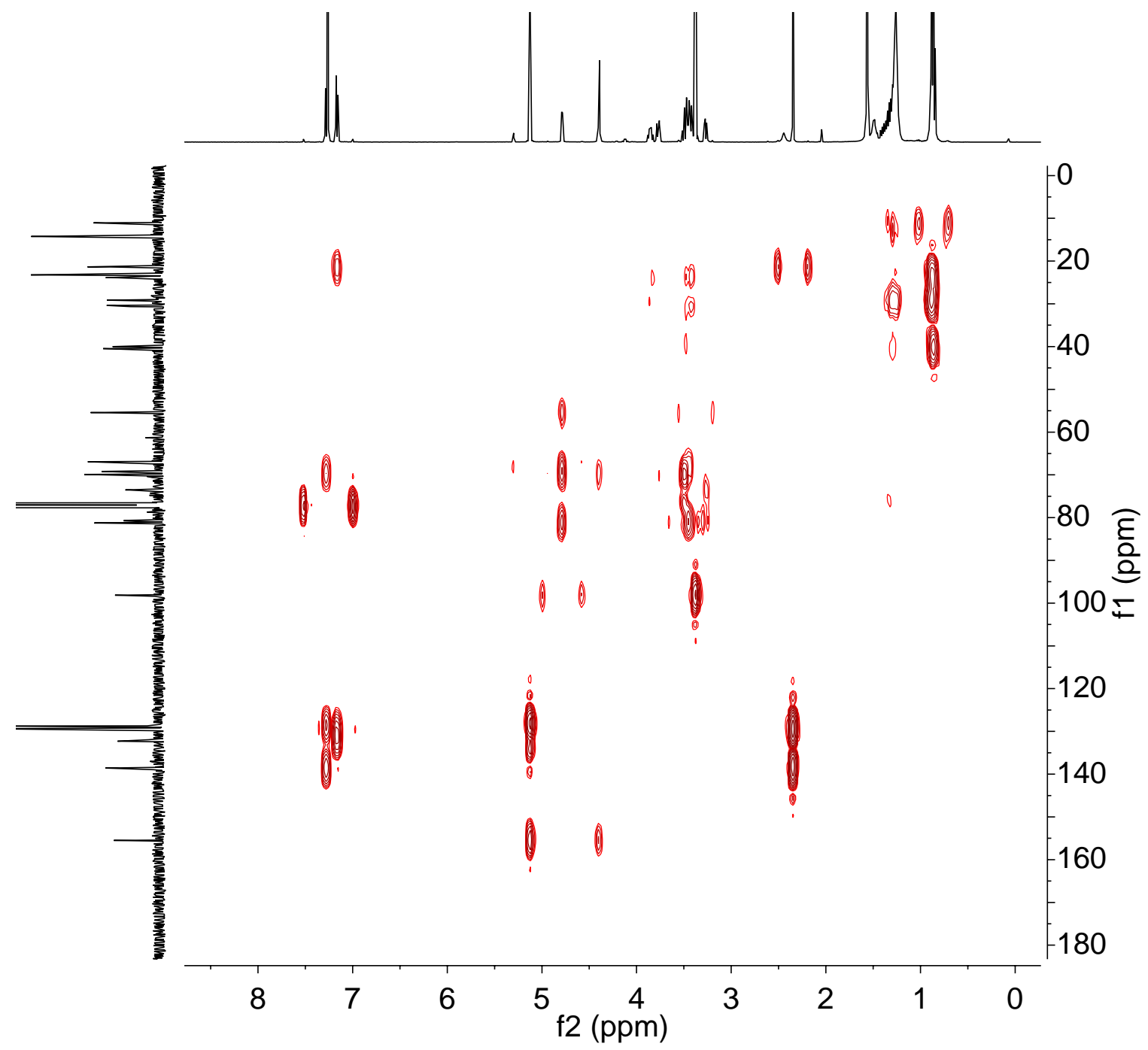

Figure S19. HMBC spectrum (400 MHz for $\left.{ }^{1} \mathrm{H}\right)$ of $\mathrm{GC}\left(\mathrm{EHE}^{2}\right)$ unimer isomer $\mathbf{I}$ in $\mathrm{CDCl}_{3}$. 


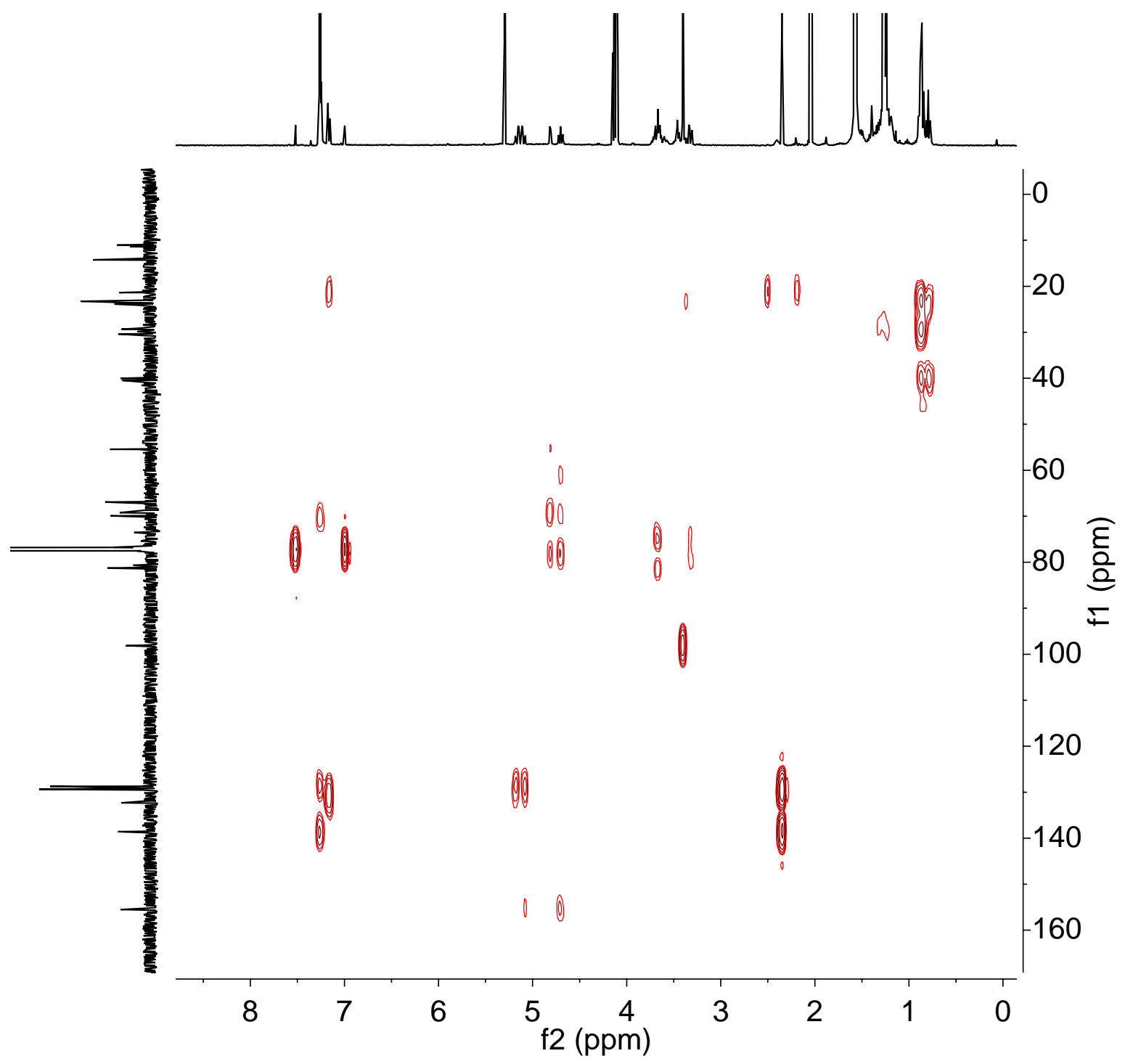

Figure S20. $\mathrm{HMBC}$ spectrum $\left(400 \mathrm{MHz}\right.$ for $\left.{ }^{1} \mathrm{H}\right)$ of $\mathrm{GC}\left(\mathrm{EHE}^{2}\right)$ unimer isomer II in $\mathrm{CDCl}_{3}$. 
(a)
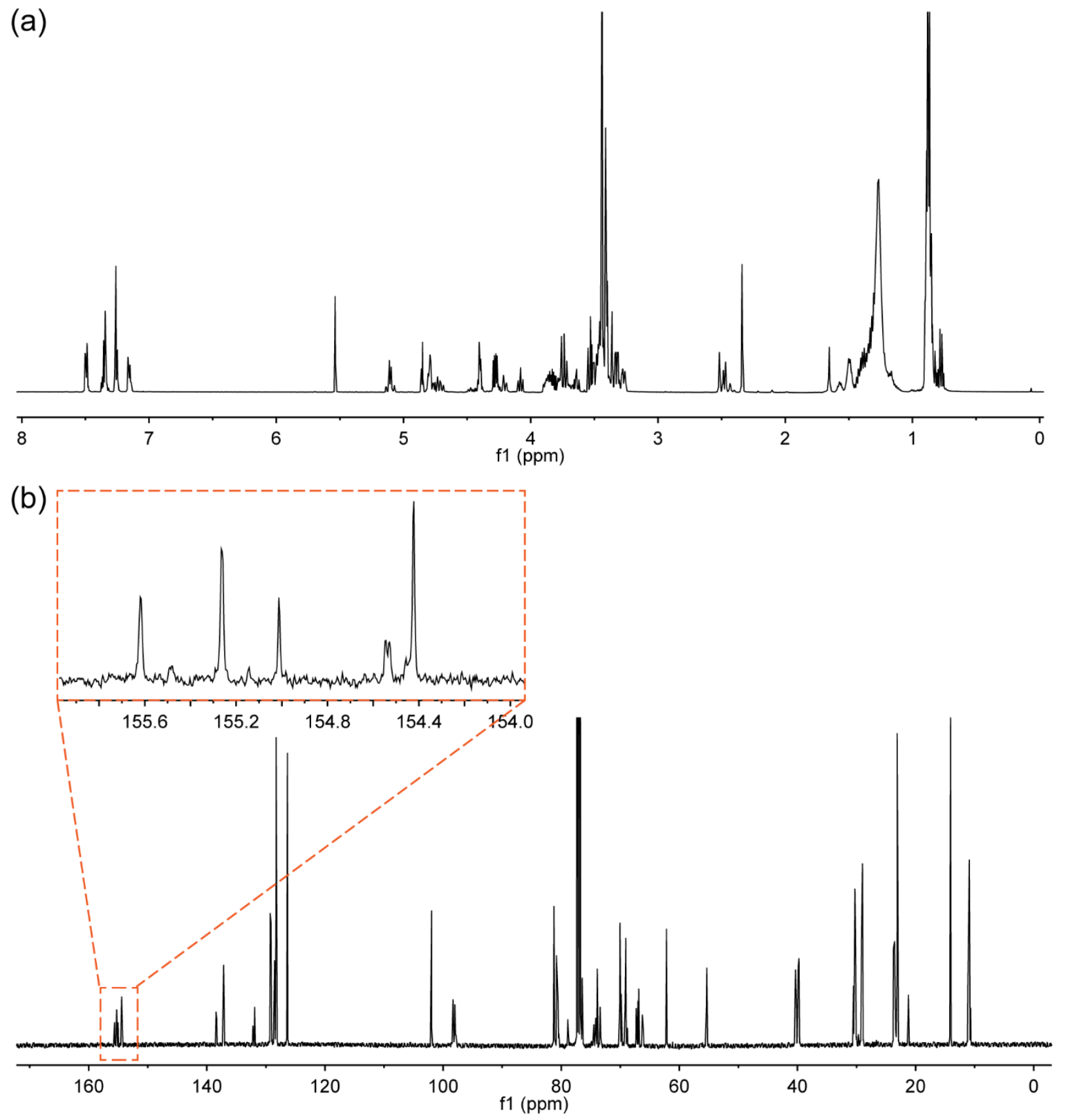

Figure S21. (a) ${ }^{1} \mathrm{H}(500 \mathrm{MHz})$ and (b) ${ }^{13} \mathrm{C}(126 \mathrm{MHz}) \mathrm{NMR}$ spectra of $\mathrm{GC}\left(\mathrm{EHE}^{2}\right)$ dimer isomer mixture in $\mathrm{CDCl}_{3}$. 


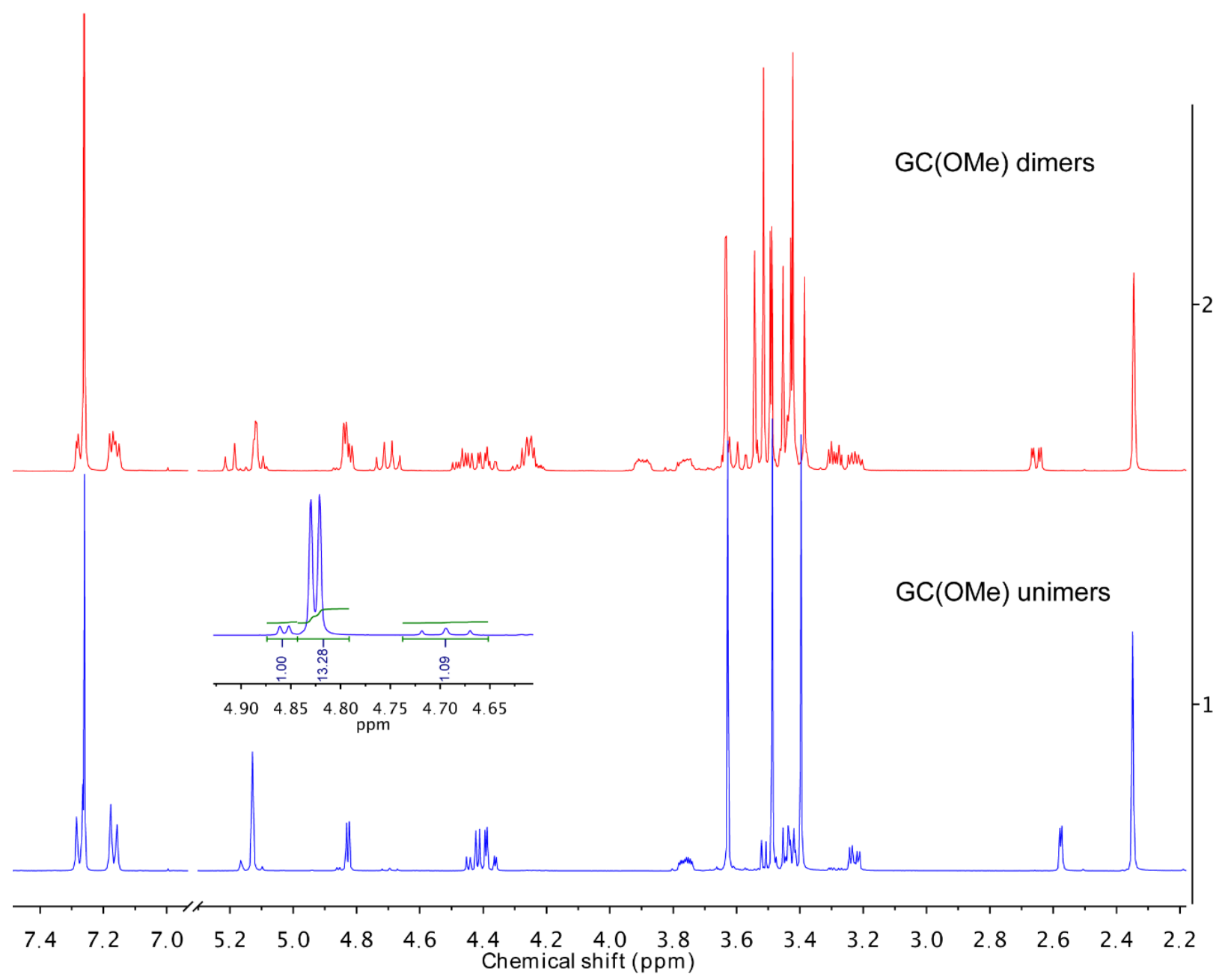

Figure S22. ${ }^{1} \mathrm{H}$ NMR (400 $\left.\mathrm{MHz}, \mathrm{CDCl}_{3}\right)$ spectra of $\mathrm{GC}(\mathrm{OMe})$ unimers and dimers. 
(a)

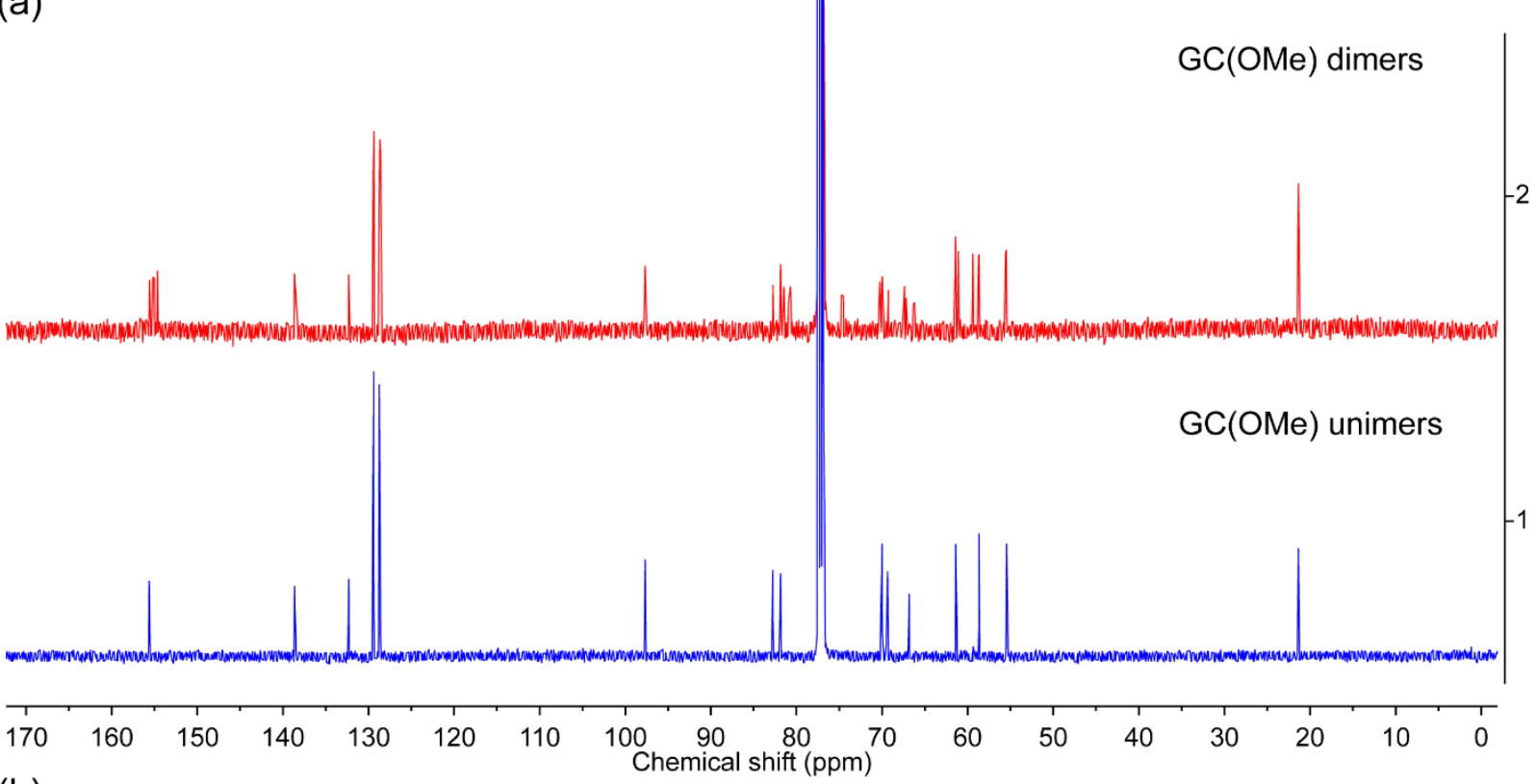

(b)

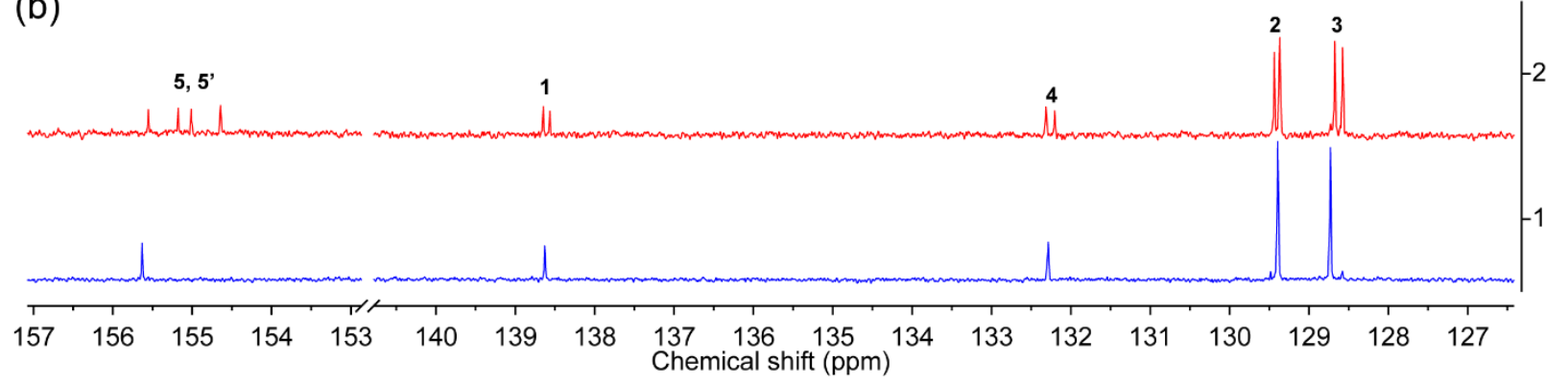

(c)

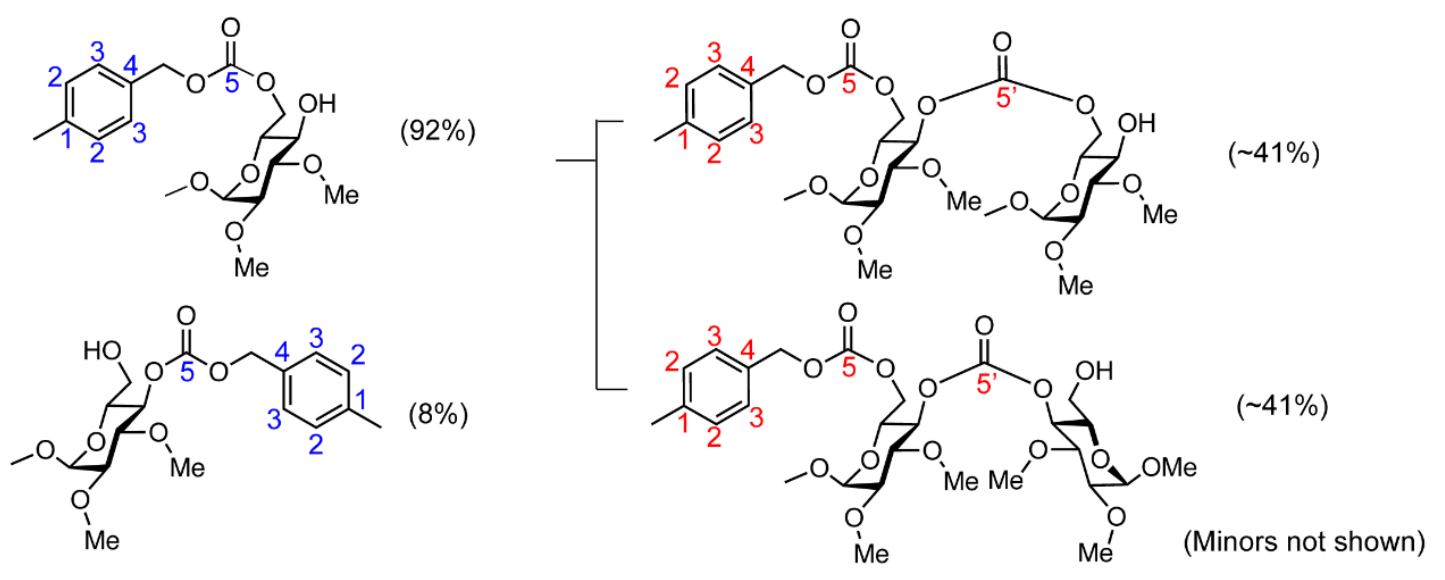

Figure S23. (a-b) ${ }^{13} \mathrm{C}$ NMR $\left(100 \mathrm{MHz}, \mathrm{CDCl}_{3}\right)$ spectra of $\mathrm{GC}(\mathrm{OMe})$ unimers and dimers. Red curve (dimers) in (b) presenting a 1:1:1:1 carbonyl peak ratio for 5 and $\mathbf{5}^{\prime}$. (c) The structures of unimers and dimers. 

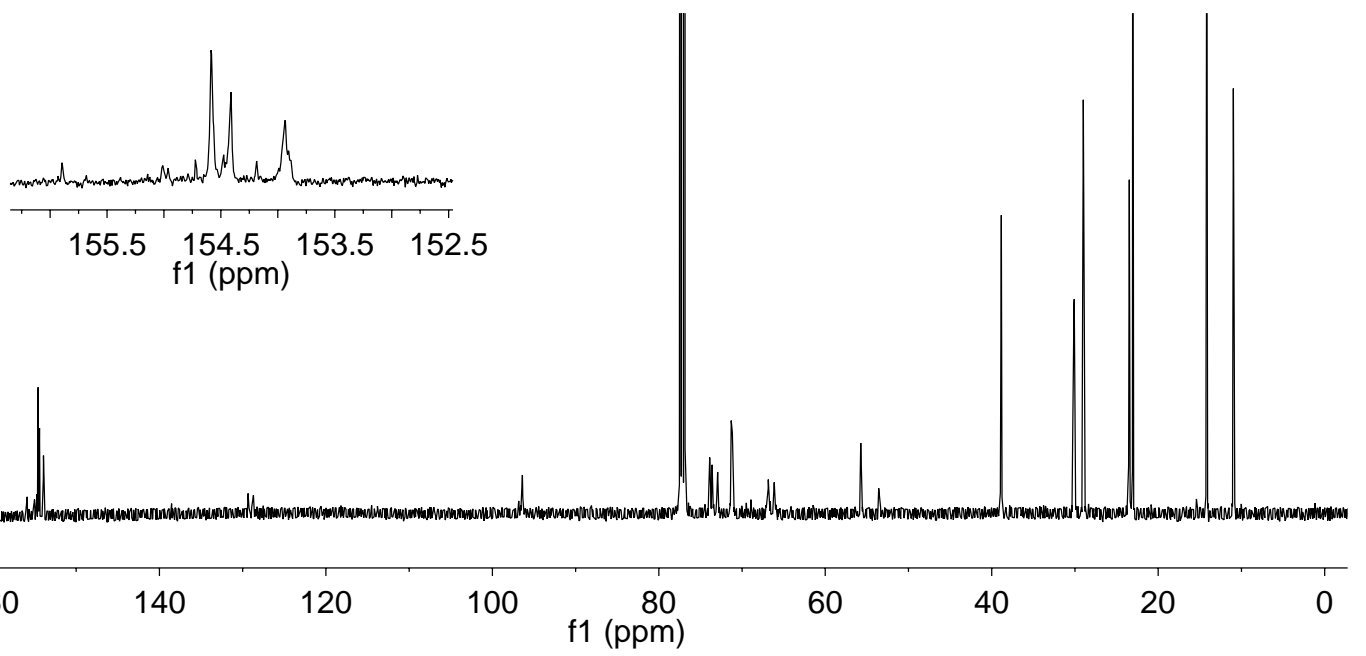

Figure S24. ${ }^{13} \mathrm{C}$ NMR $\left(126 \mathrm{MHz}, \mathrm{CDCl}_{3}\right)$ spectra of $\mathrm{PGC}\left(\mathrm{EHC}^{2}\right)$. The polymerization was conducted at room temperature.
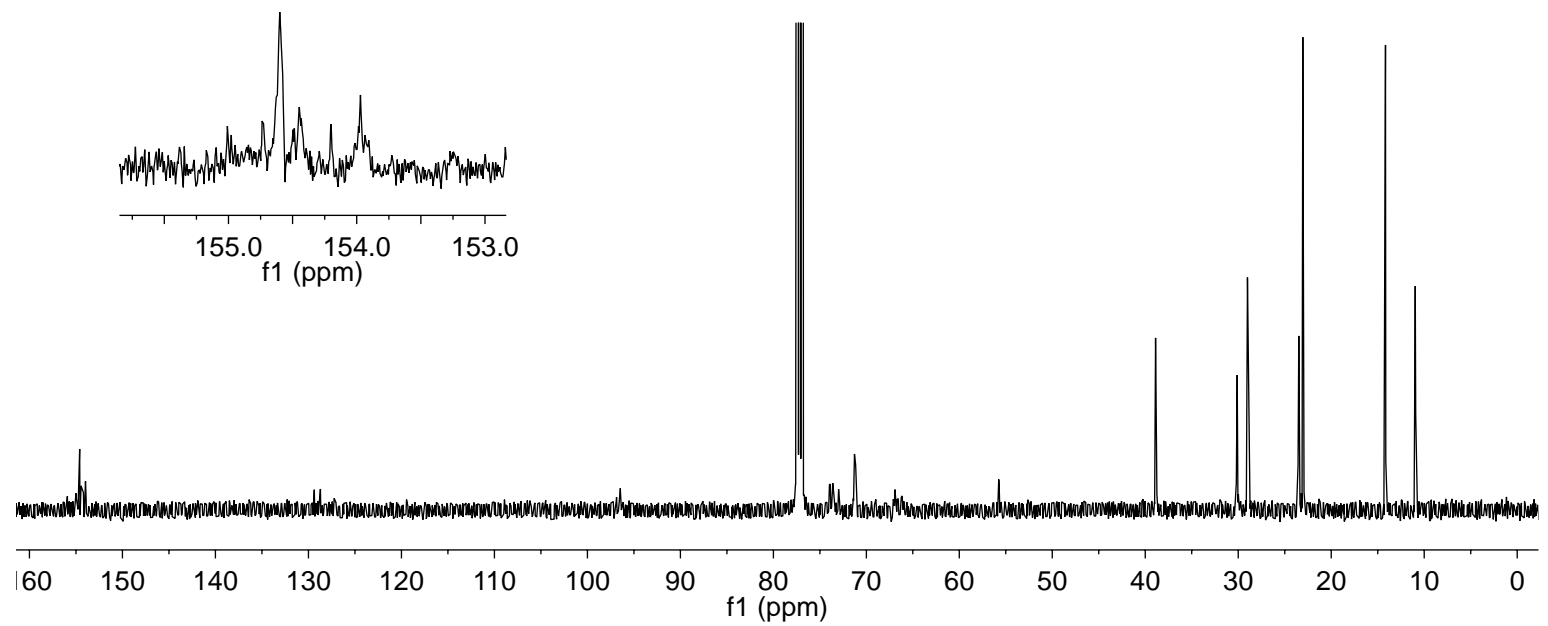

Figure S25. ${ }^{13} \mathrm{C}$ NMR spectrum of $\mathrm{PGC}\left(\mathrm{EHC}^{2}\right)$ synthesized using $\mathrm{DBU}$ at $-78{ }^{\circ} \mathrm{C}$. 


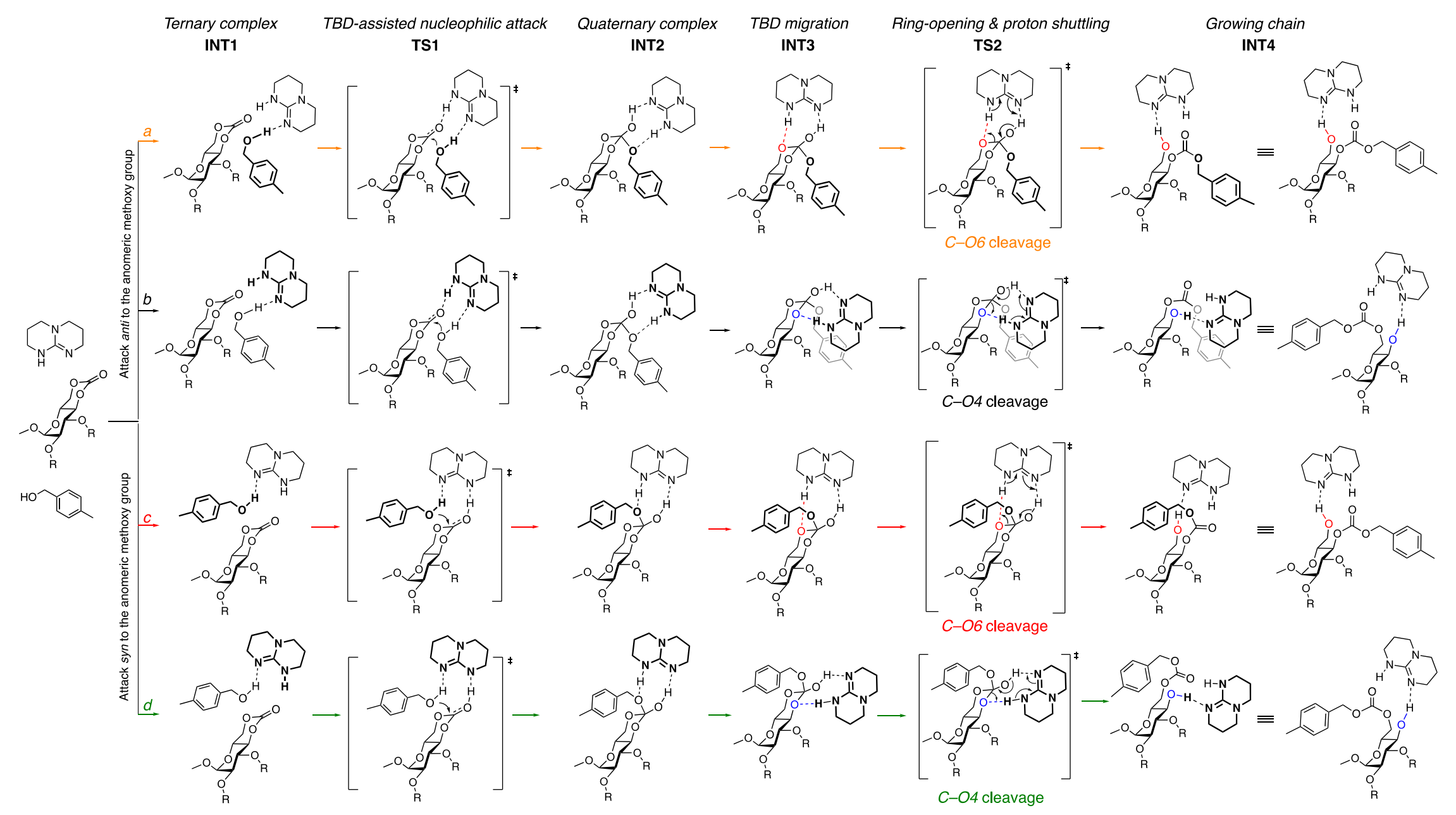

Figure S26. Four pathways $(a, b, c, d)$ of the initiation step of the ROP of 4,6-D-glucose carbonate, catalyzed by TBD and initiated by 4-MeBnOH. $\mathrm{R}=$ side chain protecting group, alkyl or alkoxylcarbonyl groups. 


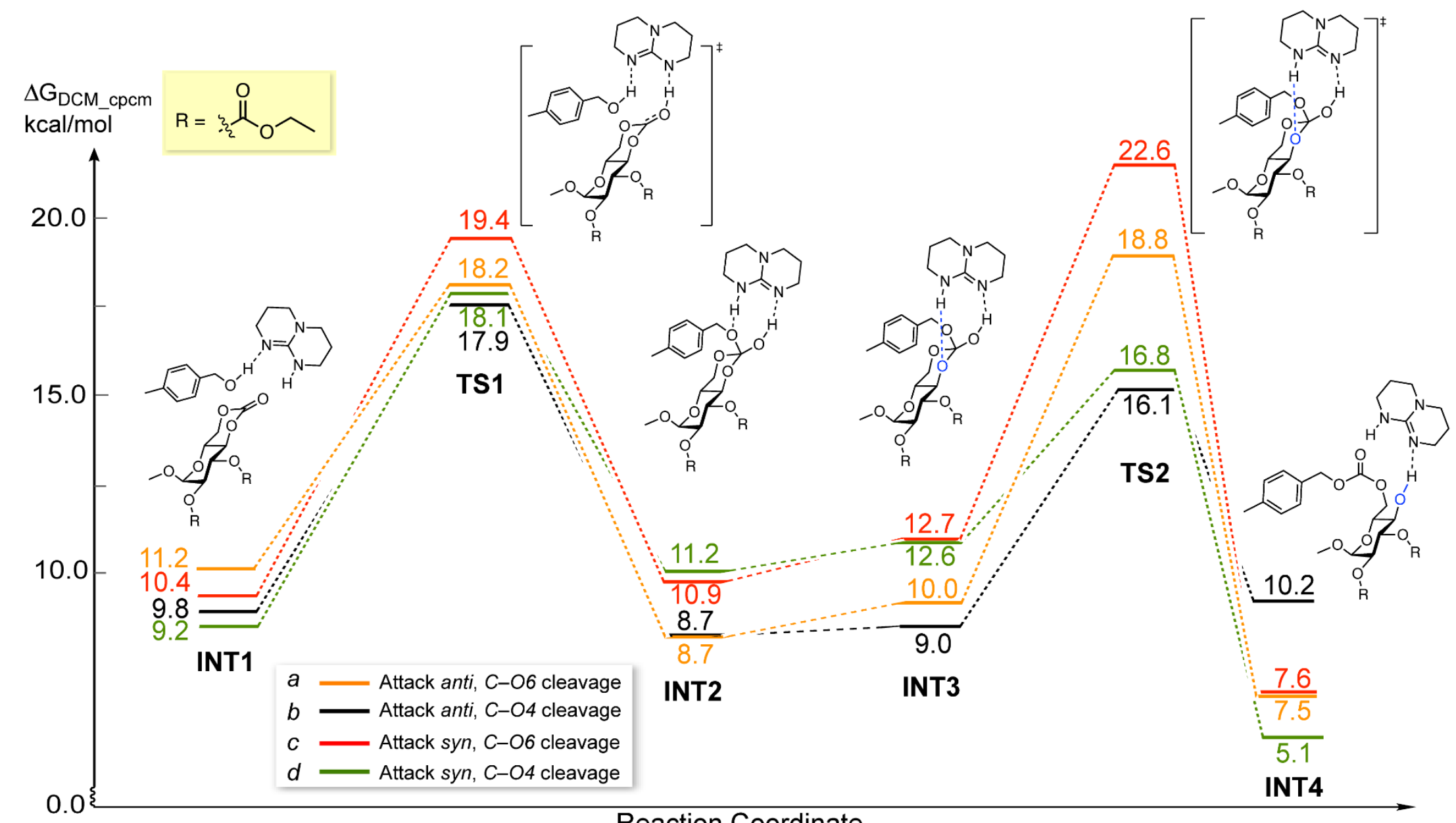

Figure S27. Gibbs free energy profile for the ring-opening initiation of glucose carbonate monomers, $\mathbf{R}=\mathbf{e t h y l o x y c a r b o n y l ,}$ catalyzed by TBD and initiated by 4-MeBnOH. 


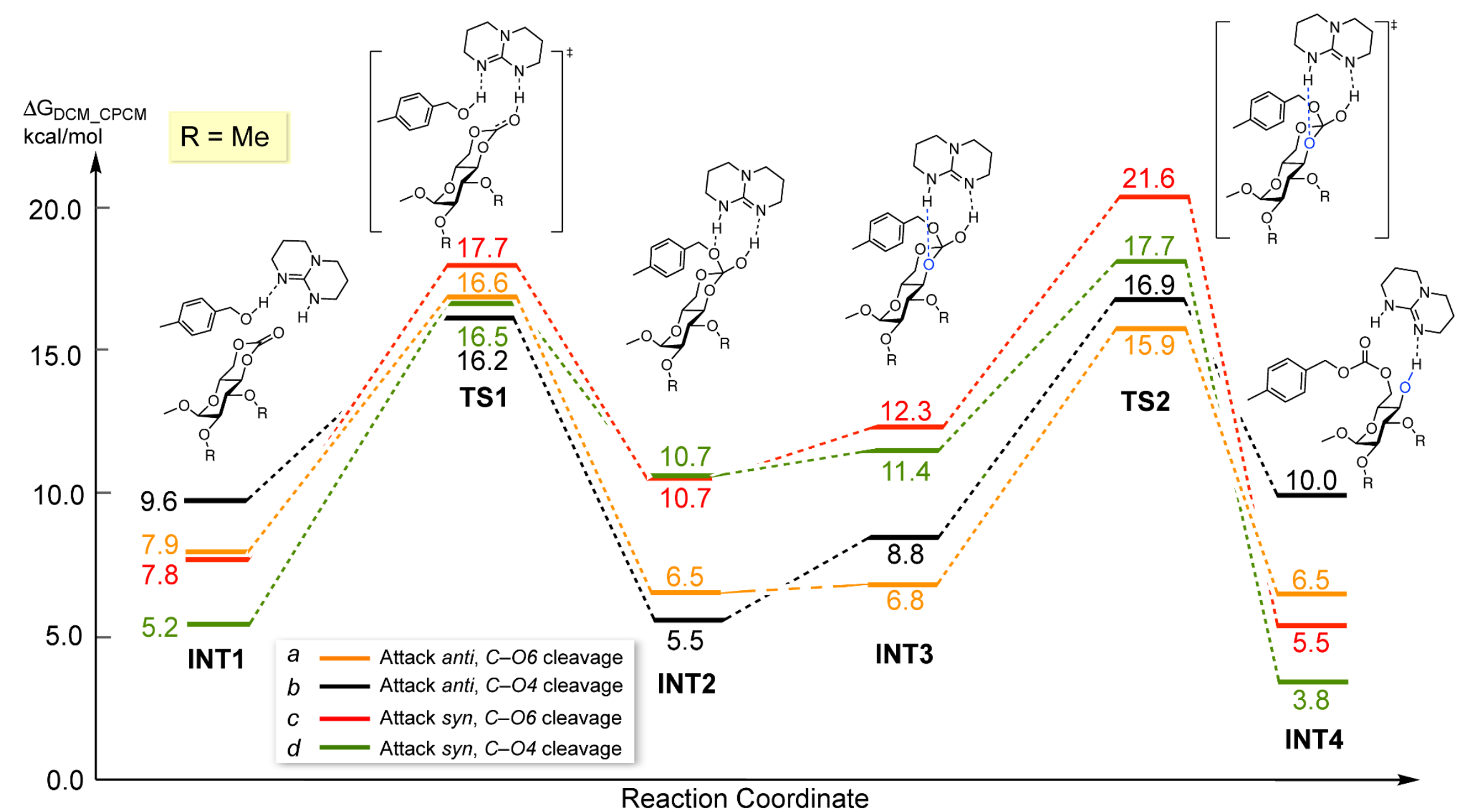

Figure S28. Gibbs free energy profile for the ring-opening initiation of glucose carbonate monomers, $\mathbf{R}=\mathbf{m e t h o x y l}$, catalyzed by TBD and initiated by $4-\mathrm{MeBnOH}$. 


\section{Details of computational chemistry}

All geometries of reactants, transition states (TSs), and intermediates were fully optimized by Gaussian 16, B.01 program. $^{2}$ The $\omega \mathrm{B} 97 \mathrm{XD}$ functional $^{3}$ was chosen as it includes a built-in dispersion correction which has been shown to be crucial for accuracy of structural and energetic properties, especially in bulky molecules. The $6-31+\mathrm{G}(\mathrm{d})$ basis set ${ }^{4}$ was used for the molecule. In addition to that, a single $\mathrm{p}$ polarization was added to the two $\mathrm{H}$ atoms directly involved in hydrogen bonding. Geometries were optimized in DCM solvent using conductor-like polarizable continuum (CPCM) model..$^{5-6}$ Frequency calculations at the same level of theory were carried out to verify all stationary points as minima (zero imaginary frequency) and transition states (one imaginary frequency). Cartesian coordinates of all the stationary points are available in .xyz format in the zip files.

\section{References}

(1) Song, Y.; Ji, X.; Dong, M.; Li, R.; Lin, Y. N.; Wang, H.; Wooley, K. L., Advancing the Development of Highly-Functionalizable Glucose-Based Polycarbonates by Tuning of the Glass Transition Temperature. J. Am. Chem. Soc. 2018, 140 (47), 16053-16057. doi: 10.1021/jacs.8b10675

(2) Frisch, M. J.; Trucks, G. W.; Schlegel, H. B.; Scuseria, G. E.; Robb, M. A.; Cheeseman, J. R.; Scalmani, G.; Barone, V.; Petersson, G. A.; Nakatsuji, H.; Li, X.; Caricato, M.; Marenich, A. V.; Bloino, J.; Janesko, B. G.; Gomperts, R.; Mennucci, B.; Hratchian, H. P.; Ortiz, J. V.; Izmaylov, A. F.; Sonnenberg, J. L.; Williams; Ding, F.; Lipparini, F.; Egidi, F.; Goings, J.; Peng, B.; Petrone, A.; Henderson, T.; Ranasinghe, D.; Zakrzewski, V. G.; Gao, J.; Rega, N.; Zheng, G.; Liang, W.; Hada, M.; Ehara, M.; Toyota, K.; Fukuda, R.; Hasegawa, J.; Ishida, M.; Nakajima, T.; Honda, Y.; Kitao, O.; Nakai, H.; Vreven, T.; Throssell, K.; Montgomery Jr., J. A.; Peralta, J. E.; Ogliaro, F.; Bearpark, M. J.; Heyd, J. J.; Brothers, E. N.; Kudin, K. N.; Staroverov, V. N.; Keith, T. A.; Kobayashi, R.; Normand, J.; Raghavachari, K.; Rendell, A. P.; Burant, J. C.; Iyengar, S. S.; Tomasi, J.; Cossi, M.; Millam, J. M.; Klene, M.; Adamo, C.; Cammi, R.; Ochterski, J. W.; Martin, 
R. L.; Morokuma, K.; Farkas, O.; Foresman, J. B.; Fox, D. J. Gaussian 16 Rev. C.01, Wallingford, CT, 2016.

(3) Chai, J.-D.; Head-Gordon, M., Long-range corrected hybrid density functionals with damped atom-atom dispersion corrections. Phys. Chem. Chem. Phys. 2008, 10 (44), 6615-6620. doi: 10.1039/B810189B

(4) Ditchfield, R.; Hehre, W. J.; Pople, J. A., Self-consistent molecular-orbital methods. IX. An extended Gaussian-type basis for molecular-orbital studies of organic molecules. J. Chem. Phys. 1971, 54 (2), 724-728. doi: https://doi.org/10.1063/1.1674902

(5) Barone, V.; Cossi, M., Quantum Calculation of Molecular Energies and Energy Gradients in Solution by a Conductor Solvent Model. J. Phys. Chem. A 1998, 102 (11), 1995-2001. doi: 10.1021/jp9716997

(6) Cossi, M.; Rega, N.; Scalmani, G.; Barone, V., Energies, structures, and electronic properties of molecules in solution with the C-PCM solvation model. J. Comput. Chem. 2003, 24 (6), 669681. doi: $10.1002 / \mathrm{jcc} .10189$ 